\title{
Development of a small and transportable de-icing/anti-icing drone-mounted system. Part 1: System design
}

\author{
Eric Villeneuve, Eric Karmouch, and Xavier Boulerice
}

\begin{abstract}
The icing of aircraft on the ground is an important flight safety issue. Aircraft must be de-iced and anti-iced to remove and protect the aircraft from freezing and frozen contamination, respectively, before and during takeoff. Winter de-icing and anti-icing operations are nonetheless costly, require a significant amount of time, and rely on extensive infrastructures. The essential equipment is often not available at smaller airports and remote locations, thereby preventing departures under a range of winter conditions. For sites located in northern Canada, this limitation results in frequent takeoff delays or cancellations during a significant portion of the year. As part of Canada's Department of National Defence Innovation for Defence Excellence and Security research program, this study aimed to develop a practical solution to mitigate these limitations. This solution involves mounting a ground de-icing/anti-icing system onto a drone for a system that can be readily acquired and stored at smaller airports and remote locations or even be transported within the aircraft itself to ensure the possibility of performing de-icing/anti-icing operations at sites lacking the standard infrastructure. This paper presents the conception and design of a drone-based system that should allow winter operations at small and remote airports where it is not yet available. To do so, a spraying system satisfying the industry requirements is designed and integrated to a selected drone. The calculations were theoretically confirmed as a concept, and a prototype was built to perform laboratory and flight test in the next part of the study.
\end{abstract}

Key words: development, de-icing, anti-icing, drone, mounted.

Résumé : Le givrage des aéronefs au sol est une importante question de sécurité de vol. Les aéronefs doivent être soumis au dégivrage et à l'antigivrage afin d'éliminer la contamination par le gel et de protéger l'aéronef contre le gel et la contamination par le gel avant et pendant le décollage. Les opérations de dégivrage et d'antigivrage hivernal sont néanmoins coûteuses, prennent beaucoup de temps et nécessitent de vastes infrastructures. L'équipement essentiel n'est souvent pas disponible dans les petits aéroports et les endroits éloignés, ce qui empêche des départs dans diverses conditions hivernales. Pour les sites dans le nord du Canada, cette limitation entraîne des retards de décollage ou des annulations fréquentes pendant une partie importante de l'année. Dans le cadre du programme de recherche "Innovation pour la défense, l'excellence et la sécurité » du ministère de la Défense nationale, cette étude visait à élaborer une solution pratique pour atténuer ces entraves. Cette solution consiste à installer un système de dégivrage/antigivrage au sol sur

\footnotetext{
Received 21 September 2021. Accepted 25 January 2022.
}

E. Villeneuve. Anti-Icing Materials International Laboratory, Université du Québec à Chicoutimi, Chicoutimi, Quebec G7H 6B6, Canada.

E. Karmouch. Chief Technology Officer, Robotics Centre, Ottawa, ON K1S 5J3, Canada.

X. Boulerice. Mechanical Designer, Tungsten Collaborative, Ottawa, ON K1Y 4R1, Canada.

Corresponding author: Eric Villeneuve (e-mail: eric1_villeneuve@uqac.ca).

(C) 2022 The Author(s). This work is licensed under a Creative Commons Attribution 4.0 International License (CC BY 4.0), which permits unrestricted use, distribution, and reproduction in any medium, provided the original author(s) and source are credited. 
un drone qui peut être facilement acquis et entreposé dans de petits aéroports et aux endroits éloignés ou même transporté à l'intérieur d'un aéronef pour assurer les opérations de dégivrage et d'antigivrage sur des sites dépourvus d'infrastructure standard. Ce document présente la conception d'un système de drones qui permettrait de procéder aux opérations hivernales dans les petits aéroports et les aéroports éloignés où les opérations ne sont pas encore disponibles. Pour ce faire, un système de pulvérisation satisfaisant aux exigences de l'industrie est conçu et intégré à un drone sélectionné. Les calculs effectués ont ensuite confirmé théoriquement le concept et un prototype est construit afin d'effectuer des essais en laboratoire et en vol dans la prochaine partie de l'étude. [Traduit par la Rédaction]

Mots-clés : développement, dégivrage, antigivrage, drone, monté.

\section{Introduction}

The icing of aircraft on the ground is an important flight safety issue. During aircraft landing or the boarding of passengers, aircraft can be subjected to icing from various forms of precipitation, including freezing rain, freezing drizzle, snow, and ice pellets (Association of European Airlines 1992; Association of European Airlines 2009). Icing or other types of accumulated contamination must be removed before the aircraft taxies to the runway (Transport Canada 2019). Cleaning the vehicle of frozen contamination involves the aircraft being moved to a de-icing station prior to takeoff. A SAE AMS 1424 Type I fluid (SAE International 2020) is sprayed at an elevated temperature, around $65{ }^{\circ} \mathrm{C}$, and at high pressure to remove frozen contaminants. This fluid consists mostly of water, glycol, and some additives. Once the contamination has been removed, the aerial vehicle is anti-iced by applying SAE AMS 1428 Type II, III, or IV (SAE International 2016) fluids. These fluids are complex non-Newtonian pseudoplastic fluids, having viscosities that are inversely proportional to the applied shear stress (shear thinning). Their pseudoplastic nature and high viscosity prevent them from flowing too rapidly off the curved structure of the aircraft and allow them to absorb a maximum amount of the freezing and already frozen contaminants. During the takeoff acceleration, airflow around the aircraft creates shear stress on the fluid, diminishing its viscosity and allowing the fluid to flow off the aircraft, thereby greatly reducing its impact on the lift coefficient of the aircraft. These fluids function as an antiicing protection system and allow the aircraft to taxi along the runway and safely takeoff, adhering to the "Clean Aircraft Concept". This concept, mandatory in Federal Aviation Administration and Transport Canada regulations, states that "No person may take off an aircraft when frost, ice, or snow is adhering to the wings, control surfaces, propellers, engine inlets, or other critical surfaces of the aircraft..." (Transport Canada 2004).

These fluids can only absorb a maximum quantity of precipitation before contamination begins to re-accumulate and (or) adhere to the aircraft surface. These fluids are submitted to various endurance and holdover time tests to measure the time within which they are effective at protecting the aircraft. The SAE AS 5901 water spray endurance test (SAE International 2019) and the SAE ARP 5718 process to obtain holdover timetables (SAE International 2008) are examples of such tests. The holdover timetables give the maximum time that the fluid protects an aircraft under a multitude of atmospheric conditions for each fluid product. If an aircraft is submitted to precipitation beyond this duration, the vehicle must again undertake a complete de-icing/anti-icing process prior to takeoff.

Winter de-icing and anti-icing operations are costly, take a significant amount of time, and require extensive infrastructures. In addition to the cost of de-icing/anti-icing operations, delayed departures and flight cancellations lead to additional losses of revenue. Moreover, the required infrastructures and equipment, e.g., de-icing trucks, make this solution impractical for smaller airports and remote locations. Both the military and the 
aviation industry require new innovative means of performing these operations at a lower cost and with less cumbersome equipment to allow de-icing/anti-icing operations at small, northern, and remote locations.

Drones, or unmanned aerial vehicles (UAV), have been used for several years for numerous civil and military applications owing to their ease of deployment, their low maintenance costs, and their ability to hover (Hayat et al. 2016). Custers (2016) provided a comprehensive overview of drone use and applications, including a discussion of drone types, payloads, current and future uses, and frequency spectrum issues. The detailed applications, relevant to this research, include drone delivery and crop spraying applications, a common drone use for agriculture. Faiçal et al. (2017) proposed an adaptive approach for UAV-based pesticide spraying in dynamic environments. The usual static configuration of drones makes them difficult to control in changing environments, e.g., variable wind speeds and direction. therefore provided various algorithms to improve UAV control to ensure more accurate spraying of pesticides from a drone.

Similar drone-based work has helped firefighters (Cervantes et al. 2018) battle high-rise fires. The described emergency responder device is a hexacopter drone having a lifting capacity of $13 \mathrm{~kg}$. This allows the drone to carry loads of sufficient size to be able to extinguish a fire within a $10 \mathrm{~m}^{2}$ area. The loads are released via a dispenser designed to maintain a stable center of gravity for the drone as it loses weight during the load dispensing. This dispenser is actioned using a servomotor controlled by the same transmitter as the drone. More recently, several studies have tested the use of drones to disinfect surfaces and structures (Ágoston et al. 2021; Jorge et al. 2021) and show promising results. Some experiments using drones as platforms for dispensing de-icing fluids on wind turbines have been conducted, including informal studies at the Norwegian University of Science and Technology, which used unmanned drones in the Arctic. Aerones, a Latvian company, also claims to have developed a drone able to apply de-icing fluids onto wind turbines (Aerones 2018). Unfortunately, no papers have yet to be published for these aforementioned studies, but Gidinceanu (2019) published a Master's thesis on the subject that confirmed the potential of the method for performing operations and decreasing the downtime due to icing, even if more research has to be conducted to handle day-to-day operations.

The study of drone flight under icing precipitation has also been recently initiated by the scientific community. The increased use of drones for a multitude of applications has created the need for great flexibility in their operating capabilities. Being able to fly under icing precipitation is becoming more important then ever. In addition to their unpublished laboratory research Liu et al. $(2017 ; 2018)$ have investigated the dynamic as well as the transient icing process over an unmanned aerial system rotating propeller model. Their research has demonstrated that the aerodynamic performances of the model tremendously degraded with the accumulation of ice. They also investigated the use of surfaces with different wettability to assess their effect on the resulting ice accretion (Liu et al. 2018). The results show the great potential of icephobic and superhydrophobic surfaces as ice protection systems for those smaller vehicles.

This research project was undertaken within the framework of Canada's Department of National Defence (DND) Breaking the Ice research program (Government of Canada 2019). The objective of this work is to develop a de-icing/anti-icing system mounted to a drone as an alternative, more flexible method of de-icing aircraft. The use of drones avoids the need for cumbersome equipment, thereby offering a more suitable solution for smaller airports. The entire de-icing/anti-icing system could even be transported inside an aerial vehicle for operations at a destination. This novel approach would allow ground operations and reduce airport delays and flight cancelations at remote and smaller airports where operation is not yet available. Here, we present the design of the de-icing/anti-icing system and its 
integration with a drone. First, the different industry standards are studied, and related requirements are highlighted. Then the spraying components of the system are selected based on those requirements (nozzle, hose, etc.), as well as a drone suitable for the task. Finally, the system design is integrated onto the drone and calculations are made to theoretically validate the concept. This work represents the first phase of a two-phase six-month project; the results of laboratory and flight tests for proof-of-concept will be presented in a second paper.

\section{De-icing/anti-icing fluid spraying system design}

To achieve the project's objectives, a de-icing/anti-icing system composed of a nozzle, portable tank, pump, heaters, and other fittings had to be developed. Any developed system must (i) be easily transportable and compact, (ii) respect industry requirements (listed and summarized at next section), (iii) use a drone capable of lifting and sustaining the complete de-icing/anti-icing operation, and (iv) be integrated with the drone while respecting the weight and size limits of the selected drone.

\subsection{De-icing/anti-icing industry standards}

Many recommended practices and standards exist in the aerospace industry in the form of aerospace recommended practice (ARP) and aerospace standard (AS) documents regarding ground de-icing/anti-icing procedures and equipment. De-icing/anti-icing methods and processes are described in ARP4737H aircraft de-icing/anti-icing methods (SAE International 1992) and AS6285 aircraft ground de-icing/anti-icing processes (SAE International 2018). These documents establish the minimum requirements for groundbased aircraft de-icing/anti-icing methods and procedures to ensure the safe operation of aircraft takeoff under icing conditions. These documents do not specify requirements for particular aircraft models. The procedures detailed in these documents are intended to effectively remove and (or) prevent the accumulation of frost, snow, slush, or ice contamination, which can seriously affect the aerodynamic performance and (or) the controllability of an aircraft. These methods use fluids qualified as AMS1424 (SAE International 2012) and AMS1428 (SAE International 2016).

De-icing methods are described using standard values and techniques with respect to the type of freezing or frozen precipitation, i.e., frost, light ice, snow, or ice. ARP4737 (SAE International 1992) specifies that for de-icing operations, fluids should be applied heated at $65{ }^{\circ} \mathrm{C}$ as close to the aircraft skin as possible to minimize heat loss. The heat in the fluid melts the frost and other light accumulations or breaks the bonds linking heavier accumulations of freezing or frozen contaminants and the aircraft. ARP4737 also requires the fluid to be applied at a minimum of $690 \mathrm{kPa}$ pressure, which will help to break the precipitationaircraft surface bond and flush off the frozen accumulations. A fan spray nozzle setting is required for frost and light accumulation removal, whereas a straight-stream pattern is preferred for heavier contaminations (SAE International 1992).

Anti-icing is performed when the aircraft surfaces are free of frozen deposits. An even layer of sufficient thickness of fluid (about $2 \mathrm{~mm}$ ) is sprayed over the critical surfaces of the aircraft. The fluid is sprayed unheated. With non-Newtonian fluids (Type II, III and IV fluids), pump speeds and nozzle spray patterns should be adjusted to produce a medium spray pattern without the high pressure or heat involved as required for de-icing fluids (Type I fluid). The process should be continuous and performed as quickly as possible. The anti-icing operations must be conducted as close to takeoff as feasible, and the anti-icing fluid must be distributed as uniformly as possible over the aircraft surface.

The drone operations are meant to be done in a similar fashion to de-icing a truck, respecting the current industry standards. However, airport regulations related to flying a 
drone on the tarmac will have to be considered to implement the technology in public transportation. Since this application is investigated for DND, the department must decide how they want to allow the drone to operate close to other aircraft during operation, as military regulations are independent from public transportation regulations and are modified internally. This task is out of the scope of this work.

\subsection{System component selection}

We used an existing test setup at the AMIL-LIMA laboratory (Université du Québec à Chicoutimi, UQAC) that had been designed to perform spraying tests with a Type I fluid in a previous project. Next, we present the individual components of this system and their characteristics.

\subsubsection{Nozzle}

SAE standards (SAE International 1986) specify that for de-icing purposes a minimum flow rate of $0.0025 \mathrm{~m}^{3} / \mathrm{s}(151 \mathrm{~L} / \mathrm{min}, 40 \mathrm{~g} / \mathrm{min})$ is required at a pressure of at least $690 \mathrm{kPa}$ (100 pounds per square inch (psi)) with the boom of the boom-truck fully elevated (at its maximum height position). The floor-to-ground height of the basket, when fully elevated, should be agreed upon between purchaser and manufacturer. In this new application, these requirements must be achieved at a maximum flight altitude estimated for the drone during operations. The drone must be able to apply the fluids on the highest part of the aircraft, which usually corresponds to the top of the tail. The highest aircraft DND operates

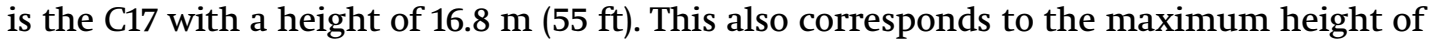
a fully extended boom of standard de-icing trucks. The target flight level for this application is between 16.8 and $18 \mathrm{~m}$ (55 and $60 \mathrm{ft}$ ) to be a viable solution. The nozzle must be able to provide the different flow patterns required during the de-icing/anti-icing operations and be able to switch between a fan-shaped spray pattern and a solid-stream pattern. The nozzle must be swivel-mounted to the hose. A temperature gauge must also be installed to record the fluid temperature at the nozzle. For anti-icing purposes, the nozzle must also support low flow, between $0.00075 \mathrm{~m}^{3} / \mathrm{s}$ and $0.00158 \mathrm{~m}^{3} / \mathrm{s}(45-95 \mathrm{~L} / \mathrm{min} ., 12-25 \mathrm{~g} / \mathrm{min}$.) and pressures lower than $483 \mathrm{kPa}(70 \mathrm{psi})$, as well as producing fan-shaped and straight-stream patterns

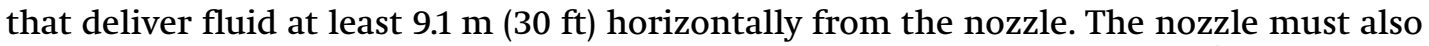
not degrade the fluids under at least $345 \mathrm{kPa}(50 \mathrm{psi})$ pressure and $0.00113 \mathrm{~m}^{3} / \mathrm{s}(68 \mathrm{~L} / \mathrm{min}$., $18 \mathrm{~g} / \mathrm{min}$.) flow rate for anti-icing and under at least $517 \mathrm{kPa}(75 \mathrm{psi})$ pressure, $0.00252 \mathrm{~m}^{3} / \mathrm{s}$ (151 L/min., $40 \mathrm{~g} / \mathrm{min}$.), and $71^{\circ} \mathrm{C}$ for de-icing with anti-icing fluids (SAE International 1992).

To apply anti-icing glycol-based fluids, an anti-icing nozzle that can operate at lower pressures and flow rates than de-icing nozzles must be selected. The nozzle included with the system was a de-icing nozzle, which was unfit for this application. Therefore, a Task Force Tips BER-HT120 (Task Force Tips Deicing 2020) was acquired, a combination nozzle designed for both de-icing and anti-icing operations. A single nozzle can be used in two steps to de-ice and prevent ice accumulation on aircraft. The operator simply selects the desired fluid delivery system pressure, and the nozzle responds automatically, a feature that is ideal for remote operations where the system is mounted onto a drone. Pattern control, switching between spray and solid-stream jets, is electronic and can be operated remotely, another important feature. Specifications for this nozzle are provided in Table 1.

\subsubsection{Hose}

A ground hose having a minimum length of $16.8 \mathrm{~m}$ ( $55 \mathrm{ft}$ ) is required. The hose must be lightweight, abrasion-resistant, compatible with glycol-based fluids, and have temperature and pressure ratings of at least $100{ }^{\circ} \mathrm{C}$ and at least $1034 \mathrm{kPa}(150 \mathrm{psi})$, respectively. For this system, an Aeroquip 1503 Series hose is selected. The Aeroquip 1503-20 (Eaton 2020) hose 
Table 1. Specifications for BER-HT120 nozzle (Task Force Tips

Deicing 2007).

\begin{tabular}{ll}
\hline Model & BER-HT120 \\
\hline Type & Combination \\
Weight & $2.9 \mathrm{~kg}(6.5 \mathrm{lbs})$ \\
Length & $25.7 \mathrm{~cm}\left(10.5^{\prime \prime}\right)$ \\
De-icing flow range & $0.0051 \mathrm{~m}^{3} / \mathrm{s} @ 800 \mathrm{kPa}(80 \mathrm{~g} / \mathrm{min}$. @ $120 \mathrm{psi})$ \\
Anti-icing flow range & $0.0013 \mathrm{~m}^{3} / \mathrm{s} @ 300 \mathrm{kPa}(20 \mathrm{~g} / \mathrm{min}$. @ $50 \mathrm{psi})$ \\
Standard coupling & $2.54 \mathrm{~cm}\left(1.0^{\prime \prime}\right)-11.5 \mathrm{NPT}$ \\
Valved & No \\
Pattern control & Electronic \\
\hline
\end{tabular}

Table 2. Specifications of the Aeroquip 1503-20 hose for use in the drone-based de-icing/anti-icing system (Aeroquip 2021).

\begin{tabular}{ll}
\hline Component & Details \\
\hline Cover material & Polyester braid \\
Maximum temperature & $121^{\circ} \mathrm{C}\left(250^{\circ} \mathrm{F}\right)$ \\
Minimum temperature & $-40{ }^{\circ} \mathrm{C}\left(-40^{\circ} \mathrm{F}\right)$ \\
Operating pressure & $4309 \mathrm{kPa}(625 \mathrm{psi})$ \\
Tube material & Nitrile \\
Burst pressure & $17237 \mathrm{kPa}(2500 \mathrm{psi})$ \\
Inside diameter & $28.4 \mathrm{~mm}\left(1.12^{\prime \prime}\right)$ \\
Minimum bend radius & $228.6 \mathrm{~mm}\left(9^{\prime \prime}\right)$ \\
Outside diameter & $38.1 \mathrm{~mm}\left(1.5^{\prime \prime}\right)$ \\
Reinforcement material & Textile inner braid, single wire braid reinforcement \\
Vacuum & $67.7 \mathrm{kPa}(20 \mathrm{inHg})$ \\
Weight & $0.68 \mathrm{~kg} / \mathrm{m}(0.52 \mathrm{lb} / \mathrm{ft})$ \\
\hline
\end{tabular}

fits the TFT BER-HT120 nozzle (Eaton 2020) and exceeds the required minimum characteristics (Table 2).

\subsubsection{Pump}

A positive displacement type pump must be used with anti-icing fluids and must not degrade the fluids under at least $483 \mathrm{kPa}(70 \mathrm{psi})$ pressure and $0.00113 \mathrm{~m}^{3} / \mathrm{s}(68 \mathrm{~L} / \mathrm{min}$., $18 \mathrm{~g} / \mathrm{min}$.). For de-icing fluids, a minimum flow rate of $0.00252 \mathrm{~m}^{3} / \mathrm{s}(151 \mathrm{~L} / \mathrm{min}$., $40 \mathrm{~g} / \mathrm{min}$.) is required at a pressure of at least $690 \mathrm{kPa}(100 \mathrm{psi})$. The pump must also be equipped with a fluid pressure gauge. The pump included with the existing AMIL-LIMA setup was a ColeParmer DB15 series magnetic-drive seal-less centrifugal pump (DB15P-3-M215) powered by a 2-HP Leeson 3450 RPM 56C TEFC motor (model C6T34FK44E). This pump and motor combination (Fig. 1) can provide a flow rate around $0.00630 \mathrm{~m}^{3} / \mathrm{s}(378 \mathrm{~L} / \mathrm{min} ., 100 \mathrm{~g} / \mathrm{min}$.), a head of $22 \mathrm{~m}$ (72 ft), and a pressure of $621 \mathrm{kPa}(90 \mathrm{psi})$, which comply with the requirements listed above taken from ARP4737H aircraft de-icing/anti-icing methods (SAE International 1992) and AS6285 aircraft ground de-icing/anti-icing processes (SAE International 2018).

\subsubsection{Tank and heater}

The tank containing the de-icing and anti-icing fluids must be composed of noncorroding material and must be able to sustain the maximum fluid temperature required for the de-icing operation. There is no specific requirement for tank capacity; this specification should be agreed upon between the purchaser and manufacturer. In this study a small tank will be used for laboratory testing for simplicity and space restrictions, while a larger tank 
Fig. 1. Magnetic-drive sealless centrifugal pump (DB15P-3-M215) and a 2-HP Leeson 3450 RPM 56C TEFC motor (model C6T34FK44E).

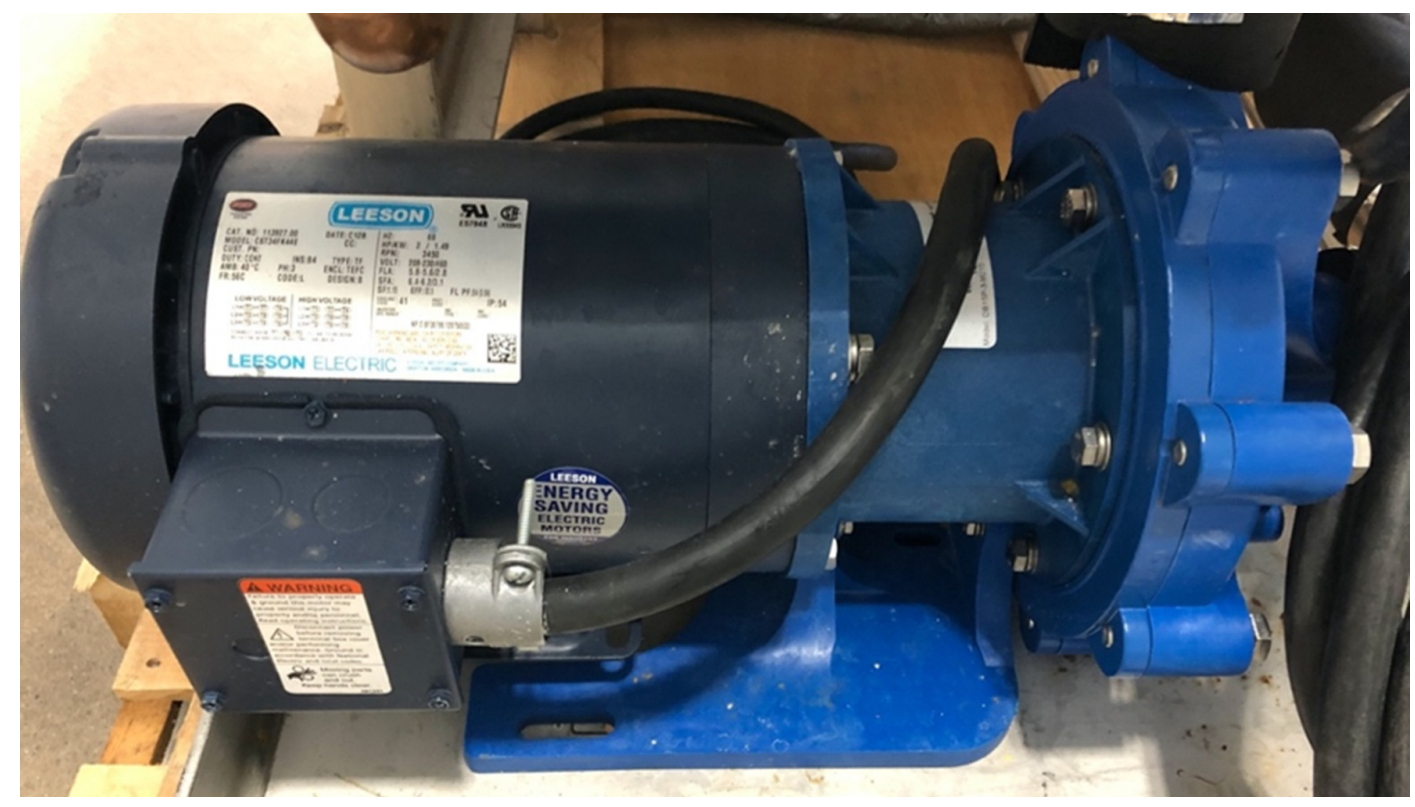

will be used for flight tests to allow uninterrupted long spraying times. For a real application, however, the tank should be sufficiently large to allow protection of the target aircraft without interruption. Split tanks should be used when different fluid types (Type I, II, III, IV) and (or) various dilutions of a fluid are used. For anti-icing fluids, the tank must contain between 0.76 and $2.27 \mathrm{~m}^{3}$ (760 and $2270 \mathrm{~L}$ ) and be protected from contamination from the Type I fluid. The tank must be designed with baffles to prevent fluid motion and starving of the pump. It must allow the mixing of Type I fluid with water at a 50:50 ratio within 15 minutes or the time it takes to heat the fluid from 15.5 to $85^{\circ} \mathrm{C}$. No thermal isolation is required between the two parts of the tank, but special attention should be paid to ensure that no significant heat transfer is obtained. There must be access to the interior of the tank and it must drain completely.

To heat the fluid for the operation, the ARP1971 proposes two systems (SAE International 1986): a flame internal combustion-type heater able to raise the temperature from 2 to $82^{\circ} \mathrm{C}$ within $1 \mathrm{~h}$ or a fast-heating design that can heat pure water running from the tank at $2{ }^{\circ} \mathrm{C}$ to the nozzle at $82{ }^{\circ} \mathrm{C}$ at a rate of at least $0.00252 \mathrm{~m}^{3} / \mathrm{s}(151 \mathrm{~L} / \mathrm{min}$., $40 \mathrm{~g} / \mathrm{min}$.) within $5 \mathrm{~min}$. The heater must be equipped with a temperature controller able to maintain a fluid temperature between 77 and $93{ }^{\circ} \mathrm{C}$ with a $\pm 3{ }^{\circ} \mathrm{C}$ tolerance. The heater must work at a continuous operation. The combustion chamber must be a closed type and respect the airport authority's operation regulations.

The available system (Fig. 2) was equipped with a $0.17 \mathrm{~m}^{3}(170 \mathrm{~L})$ main tank (Nalgene: Cole-Parmer \#S-06322-86). This tank will be used only for preliminary laboratory testing to characterize the system and will be changed for larger-scale testing in the next phase of the project, which can hold more fluid for longer spraying time. The system also contains a $500 \mathrm{~W}$ heating element, $68.5 \mathrm{~cm}\left(27^{\prime \prime}\right) \times 50 \mathrm{~cm}\left(20.5^{\prime \prime}\right) \times 68.5 \mathrm{~cm}\left(27^{\prime \prime}\right)($ length $(\mathrm{L}) \times$ width $(\mathrm{W}) \times$ height $(\mathrm{H})$ ), which is used to maintain the fluid at the desired temperature with a preheating device (Eemax model \#8208 t) for feeding the main tank through a multipurpose 
Fig. 2. The Type 1 fluid spraying test setup available at the AMIL-LIMA laboratory.
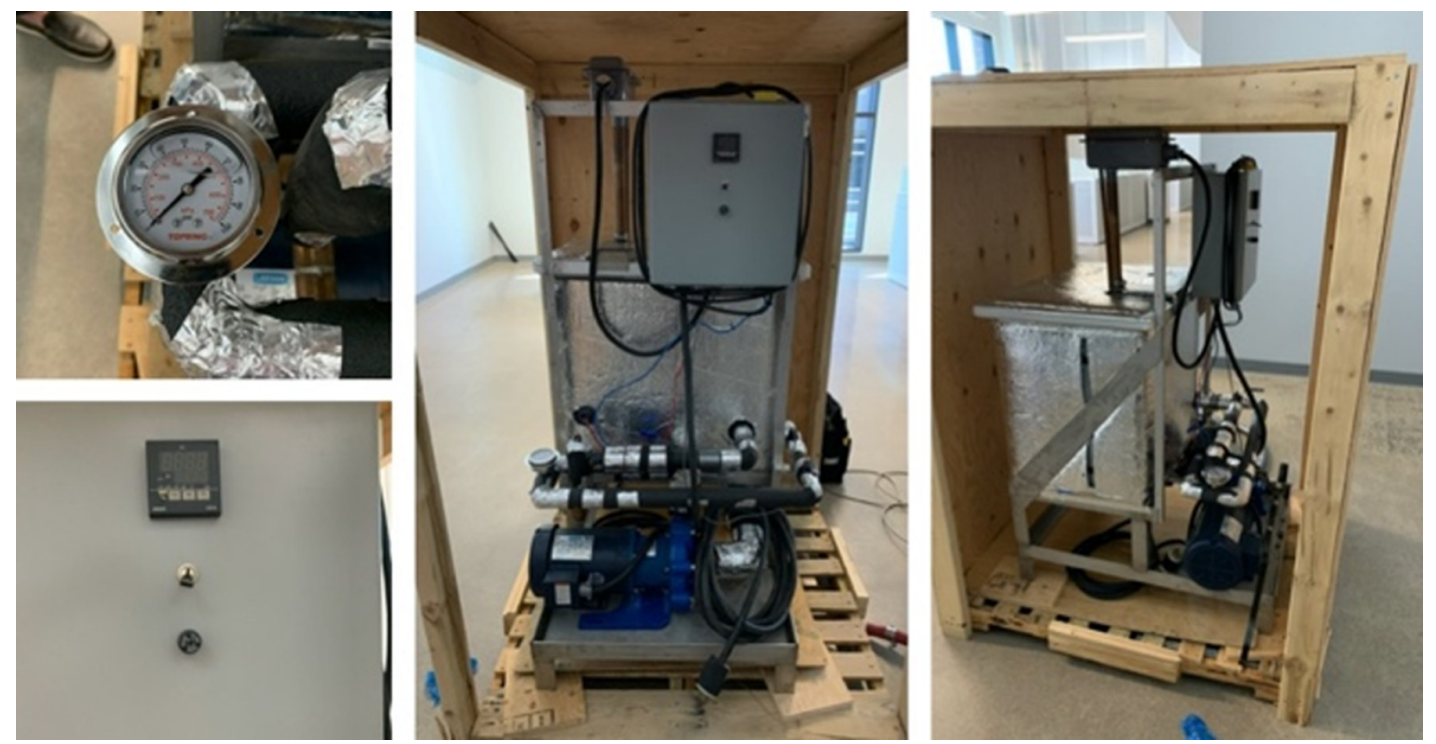

laboratory pump (Lutz B2-SS) from a storage drum filled with the test fluid. This heating system will be validated during experimental testing in the laboratory to confirm that it meets the standard requirements. This corresponds to a combination of the two accepted systems and is used because of its availability at the laboratory.

\section{Drone selection and system integration}

\subsection{Drone selection}

The requirements of the drone are payload capacity, the ability to be tethered by the hose, and the ability to handle the pressures inflicted by the pumped fluid. The Griff Aviation GRIFF 135 heavy-lift drone (Griff Aviation 2020) is selected as the drone for de-icing/anti-icing applications (Fig. 3). The GRIFF 135 was designed for the last-mile heavy transport market. It can lift a maximum payload of $55 \mathrm{~kg}(121 \mathrm{lb})$. The GRIFF 135 utilizes a dual battery set that can be charged in one hour. Moreover, the GRIFF 135 is compact for easy transportation; its folded dimensions measure $152 \mathrm{~cm}$ long $\times 79 \mathrm{~cm} \times 55 \mathrm{~cm}$ $(\mathrm{L} \times \mathrm{W} \times \mathrm{H})$. The ready-to-fly dimensions of the GRIFF 135 are $241 \mathrm{~cm} \times 249 \mathrm{~cm} \times 55 \mathrm{~cm}$ $(\mathrm{L} \times \mathrm{W} \times \mathrm{H})$ (Fig. 4). The core of the drone comprises a fuselage manufactured from aviation-grade aluminum blends and houses the flight control, avionics, and power distribution systems, and it secures the battery systems. The aircraft is equipped with a fixed landing gear with a shock-absorbing damping mechanism. The landing gear system provides shock absorption, load spreading, and load relief during takeoff, landing, and emergency situations. The aircraft is equipped with navigation and position lights with strobes to enhance its visibility and provide its orientation for observers and operators via port and starboard lights. The lights comply with European Union Aviation Safety Agency (EASA) certification specifications and "Acceptable Means of Compliance for Small Rotorcraft CS-27 Amendment 4, CS 27.1385”. The aircraft and payloads are controlled by the MicroPilot 2128HELI2 built-in flight control system. The system can be controlled by either the DC-16/DS-16 remote controller or the Horizon ${ }^{\mathrm{TM}}$ Ground Station on a tablet or laptop. The GRIFF 135 specifications are presented in Table 3. 
Fig. 3. The Griff Aviation GRIFF 135 heavy-lift drone (Credit: Griff Aviation).

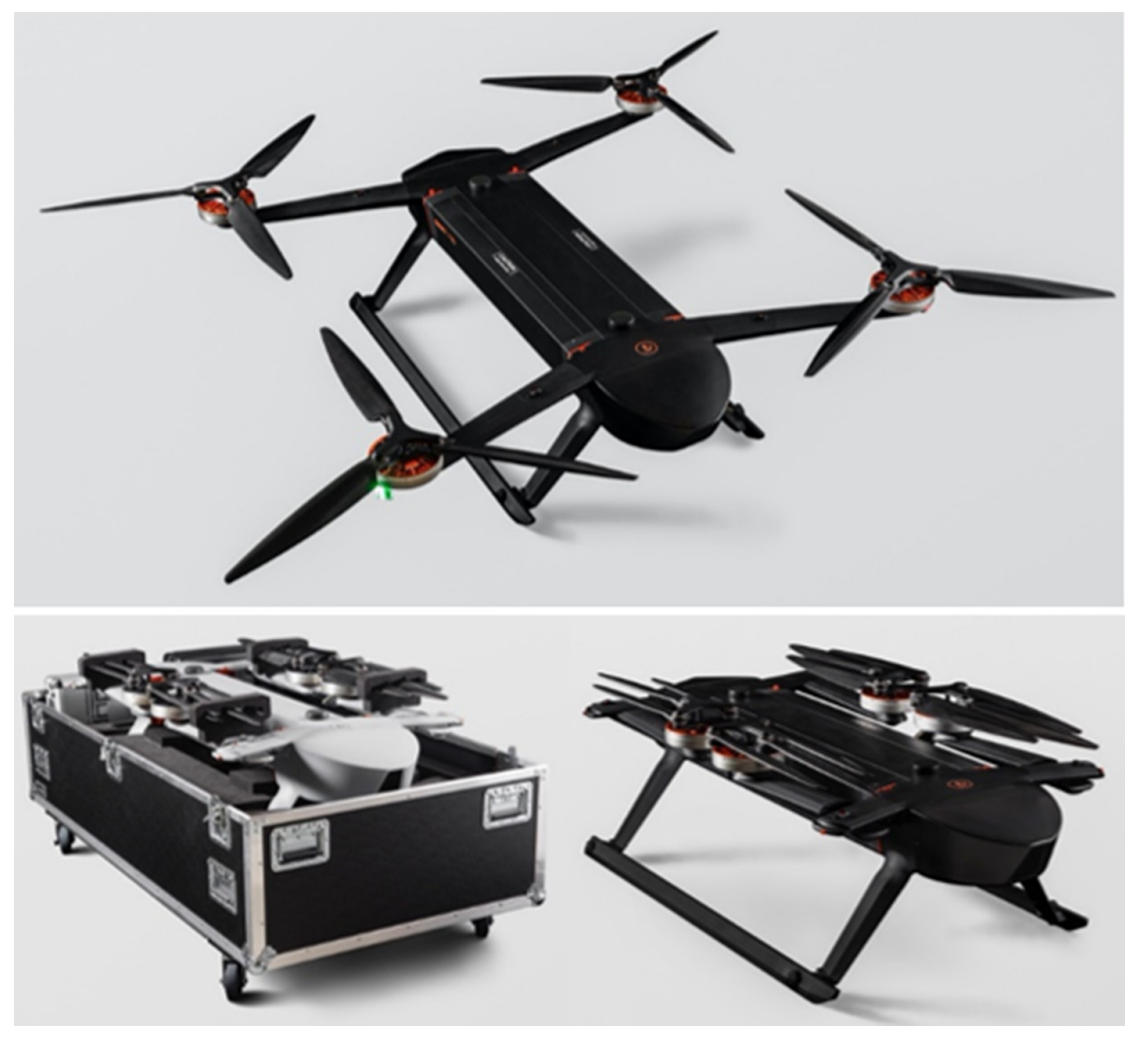

\subsection{Evaluating theoretical operational loads}

The GRIFF 135 drone has load and payload weight restrictions of a $135 \mathrm{~kg}$ maximum takeoff weight (MTOW), a payload capacity at sea level of $30 \mathrm{~kg}$, a payload capacity at $1000 \mathrm{~m}$ elevation of $22.5 \mathrm{~kg}$, and operation to a maximum of $15 \mathrm{~m} / \mathrm{s}(54 \mathrm{~km} / \mathrm{h})$ average wind speed and maximum $18 \mathrm{~m} / \mathrm{s}(64.8 \mathrm{~km} / \mathrm{h})$ wind gusts. The various loads that the drone will transport can be separated into four categories: external loads, payload fixed weight (or payload takeoff weight (PTOW)), variable hose loads, and nozzle loads. When summed, the latter three load categories must respect and not exceed the drone MTOW and drone payload capacity restrictions summarized above.

\subsubsection{External loads}

An external load can be characterized as any external force that affects the stability of the drone in flight but for which the user has no control. Maximum permissible external loads are generally set by the drone manufacturer. In this case of the GRIFF 135, the primary external loads are the average wind speed of $15 \mathrm{~m} / \mathrm{s}$ and maximum wind gusts of $18 \mathrm{~m} / \mathrm{s}$ as well as the temperature range limited to $-20^{\circ} \mathrm{C}$. An additional consideration must also be taken to other meteorological conditions, meaning freezing and frozen precipitations that can greatly affect the performances of the drone and ability to fly. Depending on the location, these limitations could pose a problem during stormy weather conditions.

To assess the applicability of the method in relation to wind loads, the wind speed at the most northern airport in the world, Alert airport, operated by Canada's Department of National Defense, is analyzed. In addition, the two most northern airports in Canada to 
Fig. 4. GRIFF 135 dimensions in millimetres, in flight and folded for transport (Credit: Griff Aviation).
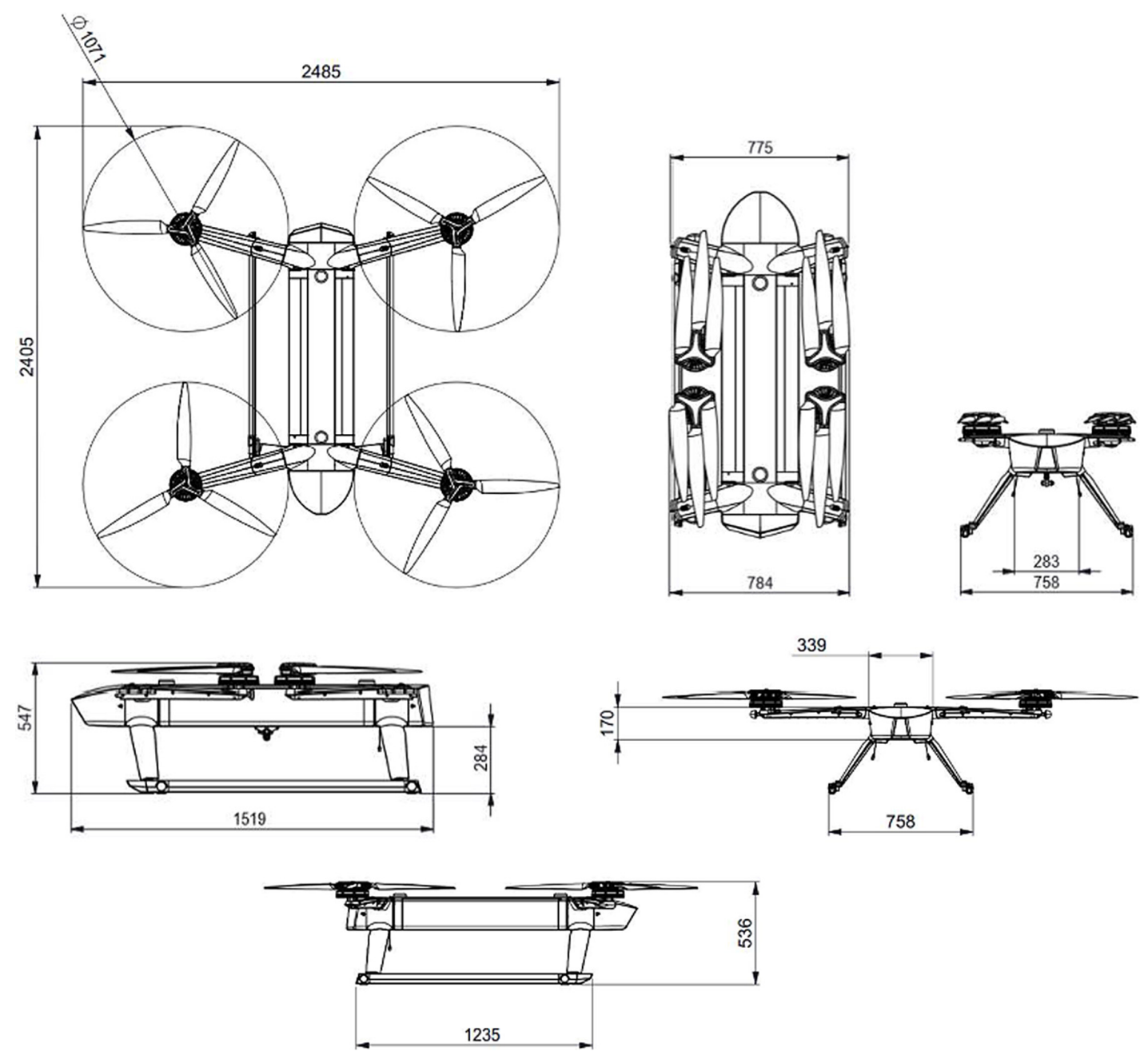

receive scheduled passenger flights, Grise Fjord Airport and Resolute Bay Airport, are also investigated. Old Crow airport, the most northern airport in Yukon, is also added to the investigation to include western Canada. Table 4 presents the number of days per year where wind speeds can reach between 14 and $17 \mathrm{~m} / \mathrm{s}$, as well as those where they can exceed $17 \mathrm{~m} / \mathrm{s}$ (Meteoblue 2021). The data clearly show that the wind is not an issue for those locations and that the drone should be able to operate about $99 \%$, or more, of the time with regards to wind conditions. The ability to operate for more than $99 \%$ of the year is a significant and major improvement for remote locations where no solution currently exists.

Table 5 presents the annual average wind speeds and the number of days per year with winds over $15 \mathrm{~m} / \mathrm{s}$ for major cities in Canada (Environment and Climate Change Canada 2021). The average wind speed for these locations is also well below the $15 \mathrm{~m} / \mathrm{s} \mathrm{limit}$ for the drone, although it is also evident that the drone would not be able to operate during the same number of days at different airports. For most of these cities, however, the drone could still operate for more than $95 \%$ of the year-the lowest is for Calgary, having a minimum of $92.5 \%$ days per year of potential operation. The probability that the drone would 
Table 3. Specifications of the Griff Aviation GRIFF 135 heavy-lift drone.

\begin{tabular}{ll}
\hline Specifications & \\
\hline Rotor diameter & $1070 \mathrm{~mm}$ \\
Flight controller & MicroPilot $2128^{\text {HELI-LRC2 }}$ \\
Ground station software & Horizon ${ }^{\text {TM }}$ \\
Ground station tablet & Getac F110 rugged tablet \\
Remote control & Jet DC-16 \\
Battery & Sony VTC6 18650, 14S22P Li-ion battery, $50.4 \mathrm{~V}$ \\
Battery capacity & $3080 \mathrm{Wh}$ \\
Charge time & Approx. 70 min \\
& \\
Operating conditions & Max. $15 \mathrm{~m} / \mathrm{s}(18 \mathrm{~m} / \mathrm{s}$ gust) \\
Wind & -20 to $40^{\circ} \mathrm{C}$ \\
Temperature & $0 \%-100 \%$ relative humidity \\
Humidity & $0-1500 \mathrm{~m}$ above mean sea level \\
Height/altitude & 0 to $40{ }^{\circ} \mathrm{C}$ \\
Battery charging temperature (ambient) & $5-7 \mathrm{~km}$, in line of sight \\
Range & $50-60 \mathrm{~km} / \mathrm{h}$ optimal (maximum speed $90 \mathrm{~km} / \mathrm{h}) 4$ motors \\
Speed & $135 \mathrm{~kg}$ \\
Maximum takeoff weight & $70 \mathrm{~kg}$ \\
Empty weight & Skids with suspension $2 \mathrm{~kg}$ \\
Landing gear & RET20 \\
Motor & $107 \mathrm{~cm} \times 28 \mathrm{~cm}\left(42^{\prime \prime} \times 11^{\prime \prime}\right)$ foldable blades $3 \mathrm{blades}$ per motor \\
Propeller &
\end{tabular}

Table 4. Wind speed information over a year for the most northern airports in Canada (Meteoblue 2021).

\begin{tabular}{lll}
\hline & $\begin{array}{l}\text { Number of days per year } \\
\text { having wind speeds between } \\
\text { Airport }\end{array}$ & $\begin{array}{l}\text { Number of days per year } \\
\text { having wind speeds above } 17 \mathrm{~m} / \mathrm{s}\end{array}$ \\
\hline Alert, Nunavut* & 2.9 & 0.4 \\
Grise Fjord, Nunavut & 2.4 & 0.5 \\
Old Crow, Yukon & 3.4 & 1 \\
Resolute Bay, Nunavut & 7.2 & 1 \\
\hline
\end{tabular}

Note: Alert is the most-northern airport in the world.

Table 5. Wind speed information over a year for major cities in Canada (Environment and Climate Change Canada 2021).

\begin{tabular}{lll}
\hline City & $\begin{array}{l}\text { Average wind } \\
\text { speed }(\mathrm{m} / \mathrm{s})\end{array}$ & $\begin{array}{l}\text { Number of days per year } \\
\text { having wind speeds } \\
\text { above } 15 \mathrm{~m} / \mathrm{s}\end{array}$ \\
\hline Calgary, Alberta & 4.0 & 28 \\
Edmonton, Alberta & 3.1 & 3 \\
Halifax, Nova Scotia & 4.2 & 18 \\
Montreal, Quebec & 3.9 & 11 \\
Ottawa, Ontario & 3.3 & 8 \\
Quebec City, Quebec & 3.6 & 7 \\
Toronto, Ontario & 4.2 & 22 \\
Vancouver, British Columbia & 3.3 & 7 \\
Winnipeg, Manitoba & 4.7 & 24 \\
\hline
\end{tabular}

not be able to operate for de-icing/anti-icing purposes is therefore quite low, and could be even lower since the drone can still tolerate wind gust up to $18 \mathrm{~m} / \mathrm{s}$. This means that the solution could still be applicable to larger airports in relation to wind loads. 
For the temperature, when looking at Alert and Resolute Bay airports, it can easily be seen that operations are required all year long, with average temperatures around $0{ }^{\circ} \mathrm{C}$, even in July (Meteoblue 2021). With a minimum temperature of operation of $-20{ }^{\circ} \mathrm{C}$, the drone could operate from April through October. However, during the coldest months, the averages are between $-26{ }^{\circ} \mathrm{C}$ and $-21^{\circ} \mathrm{C}$, meaning that even if the drone could still operate during the warmer days, between $-20^{\circ} \mathrm{C}$ and $-14{ }^{\circ} \mathrm{C}$, it would still be limited in operation. While the data show that most of the precipitations occurs over the summer and fall, it is still important that the drone is more flexible during the coldest months, where very cold conditions can be encountered even in the most southern airports in Canada. The temperature limitation is set by the battery pack used to power the drone since colder temperatures greatly reduce the performance of batteries. With the solution to tether the drone, no battery would be needed and after discussions with the manufacturer, it seems that the drone could then tolerate temperatures of $-30{ }^{\circ} \mathrm{C}$, even $-40{ }^{\circ} \mathrm{C}$, meaning that drone would be able to fly almost year-long even at the most northern airports.

The worst conditions that the drone can encounter during operation is the presence of ongoing freezing and frozen precipitation. Although frozen precipitation can still affect the vehicle, freezing precipitation, especially when accumulating on the rotors, can really hinder the aerodynamic performance and prevent the drone from safely performing the de-icing. The operation of the drone under those conditions has begun to be of interest to the scientific community in recent years. At AMIL, multiple papers on this are in varying stages of preparation. In addition, Liu et al. $(2017,2018)$ have published studies on that show the drastic effect of ice accumulation on a drone, especially the rotors. Power consumption and torque quickly and greatly increase, while thrust shows the inverse effect. Different solutions to this problem are also investigated in those studies, showing the effectiveness of thermal heating and the significant power required for this solution as well as the promising avenue of icephobic coatings (Liu et al. 2018). While it can be expected that this new research should soon lead to innovative solutions that will settle this problem, it is still too early to rely and base the approach on solutions still under development. For now, thermal heating is the ready solution and is also already used in the industry for aircraft and rotorcraft. The high energy consumption required to provide ice protection is the current drawback limiting the application of this technology for small drones where power and energy are greatly limited. However, by tethering the drone, virtually an unlimited supply of energy becomes available and thermal heating becomes a really simple and efficient solution to allow flying of the drone under most of the precipitation conditions currently established in the hold-over time guidelines (SAE International 2008), which are already the limiting conditions for fluid application. Even if some studies and investigations are still needed to design an optimal thermal ice protection system for the drone, this path shows very high potential of success. This means, however, that tethering of the drone becomes a key part of the technology, which it has always been since the beginning of the project, considering the safety at airport when flying a drone. Although tethering the drone and supplying power still need to be studied thoroughly in the next stages of the project, the fact that the drone is already attached with a hose allows us to envision that there is a high feasibility and low complexity to this approach.

\subsubsection{Payload fixed weight}

The payload fixed weight is the portion of the payload weight that remains constant regardless of altitude. The drone must carry the payload fixed weight both when on the ground and during takeoff, hence the use of the term PTOW to describe this load. The PTOW must be accounted for when calculating the drone's MTOW-135 kg for the GRIFF 135. The PTOW is a function of the the minimum required plumbing and the material and 
Table 6. Estimated payload fixed weight for the de-icing/anti-icing system on the GRIFF 135 drone.

\begin{tabular}{lllc}
\hline Item & Quantity & Weight/item $(\mathrm{kg})$ & Total weight $(\mathrm{kg})$ \\
\hline Remote TFT nozzle & 1 & 2.9 & 2.9 \\
Hose adapter & 1 & 0.2 & 0.2 \\
$4.5 \mathrm{ft}$ hose & 1 & 1.0 & 1.0 \\
Swivels & 1 & 2.2 & 2.2 \\
Connectors & 1 & 1.2 & 1.2 \\
Hose fitting & 3 & 0.6 & 1.8 \\
Other hardware & 1 & 3.1 & 3.1 \\
6 ft pipes & 3 & 0.3 & 0.9 \\
Hose and holders and tilts & 1 & 5.0 & 5.0 \\
Drone brackets & 1 & 2.5 & 2.5 \\
Total fixed payload weight & & & $\mathbf{2 0 . 8}$ \\
\hline
\end{tabular}

geometry. The PTOW can thus be minimized by controlling the material and geometries. The estimated payload for the developed system is presented in Table 6.

\subsubsection{Variable hose loads}

The loads imparted on the drone by the hose will vary as a function of altitude, hose selection, fluid selection, flow rate, and pressure. As the drone gains altitude, it must lift a longer portion of the hose (hose + the fluid it contains) off the ground. This load can be easily calculated using the following formula:

(1) ${\text { Hose } \text { Load }_{\text {Altitude }}=\text { Hose Weight }}_{\text {Altitude }}+$ Fluid Weight

(2) Hose Weight $_{\text {Altitude }}=$ Hose Linear Weight $\times$ Hose Length Off the Ground

(3) Fluid Weight $_{\text {Altitude }}=$ Fluid Density $\times$ Hose Internal Area $*$ Hose Length Off the Ground $_{\text {H }}$

It can be assumed, for the range of interest in this project (below $35 \mathrm{~m}$ ) that:

(4) Hose Length Off the Ground $_{2} \cong$ Drone Altitude

Therefore,

(5) $\quad$ Hose $\operatorname{Load}_{\text {Altitude }}=$ Drone Altitude $\times($ Hose Linear Weight $+($ Fluid Density $\times$ Hose Internal Area $)$

This only involves the lifting of those in the vertical direction and not additional movement limits in the horizontal direction. The selected Aeroquip 1503-20 hose weighs $0.68 \mathrm{~kg} / \mathrm{m}$ and has an internal volume of $6.36 \times 10^{-4} \mathrm{~m}^{2}$. Because Type 1 fluids consist mostly of water, glycol, and some additives, its density is estimated to be that of water $\left(1000 \mathrm{~kg} / \mathrm{m}^{3}\right)$ :

(6) Hose Load $_{\text {Altitude }}=$ Drone Altitude $\times 1.316$

\subsubsection{Nozzle loads}

The nozzle load is defined as the reaction force (thrust) that is imparted by the fluid on the nozzle as it leaves the nozzle tip. It is a vector acting along the nozzle center line. Because the nozzle angle can be adjusted between $0^{\circ}$ and $90^{\circ}$, the load vector can be broken into horizontal and vertical components of varying magnitude. Because the nozzle is pointing downward, the vertical component of the vector will be positive (generating lift). This will help offset some of the payload weight and will allow the drone to reach a higher 
Fig. 5. BER-HT120 remote nozzle operating range for pressure and flow rate (Credit: Task Force Tips).

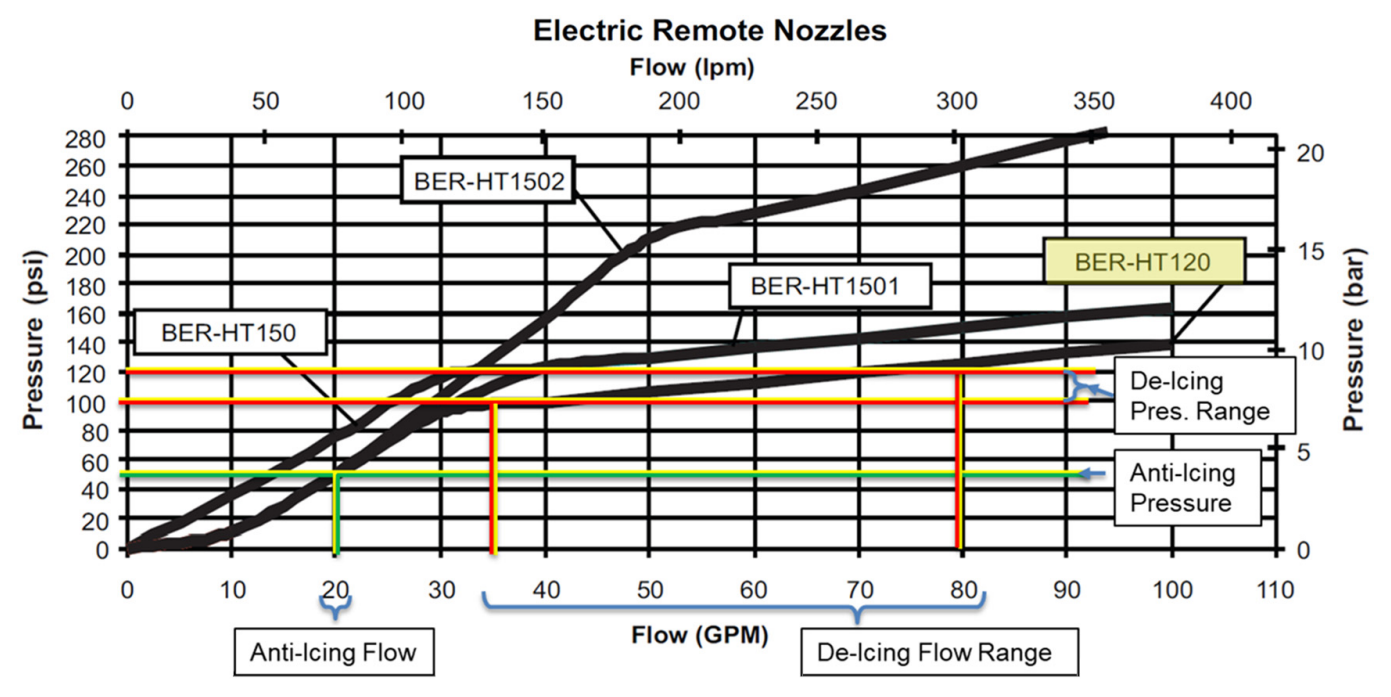

altitude while spraying de-icing/anti-icing fluids. The reaction force or thrust produced by the fluid will vary as a function of pressure, flow rate, and fluid density (Fig. 5). From the nozzle manufacturer's data sheet, the maximum reaction force (Fig. 6) or thrust generated by the nozzle is $206 \mathrm{~N}$ (21 kgf), which occurs at the nozzle maximum rated pressure and flow rate of $785 \mathrm{kPa}\left(8.3 \mathrm{kgf} / \mathrm{cm}^{2}\right)$ and $0.005 \mathrm{~m}^{3} / \mathrm{s}(300 \mathrm{~L} / \mathrm{min}$.), respectively.

\subsubsection{Final load calculation}

The force diagrams of all the forces involved are presented at Figs. 7 and 8. The payload was designed around a modular rail system for testing flexibility. Moving the components away from the drone centre of gravity increases the moment of force, as shown on the force diagrams and the resulting equations (7 to 11). The following equations apply along the length direction of the drone (Fig. 7):

(7) $\Sigma \overrightarrow{\mathrm{F}}_{z}=-$ PayloadFixedWeight - VariableHoseLoad + NozzleLoad $\times \sin \theta<0$

(8) $\Sigma \overrightarrow{\mathrm{M}}_{\mathrm{x}}=-$ NozzleLoad $\times d_{\mathrm{YG}}+$ PayloadFixedWeight $\times d_{\mathrm{YO}}-$ VariableHoseLoad $* d_{\mathrm{YP}} \neq 0$

(9) $\Sigma \vec{F}_{y}=$ NozzleLoad $\times \cos \theta>0$

With $\theta$ the angle of the nozzle, $F$ is force, and $M$ is moment of force.

While those along the width of the drone are, in addition to eq. 7, (Fig. 8):

(10) $\Sigma \overrightarrow{\mathrm{M}}_{y}=$ NozzleLoad $\times d_{\mathrm{XG}}+$ PayloadFixedWeight $\times d_{\mathrm{XO}}+$ VariableHoseLoad $\times d_{\mathrm{XP}} \neq 0$

(11) $\Sigma \vec{F}_{x}=0$

Ideally, all load vectors should be close to, and pass through, the drone's center of gravity (Figs. 9 and 10) to ensure minimal moment arm is applied to the drone and to avoid a required compensation by either the drone's software or the pilot to produce more thrust from one of the drone's four propellers. Moreover, moving the components away from the drone center of gravity quickly creates an "imbalanced" moment arm, which could cause damages to the aircraft. Zero moment arm means that all four propellers share an 
Fig. 6. BER-HT120 remote nozzle reaction forces (Credit: Task Force Tips).

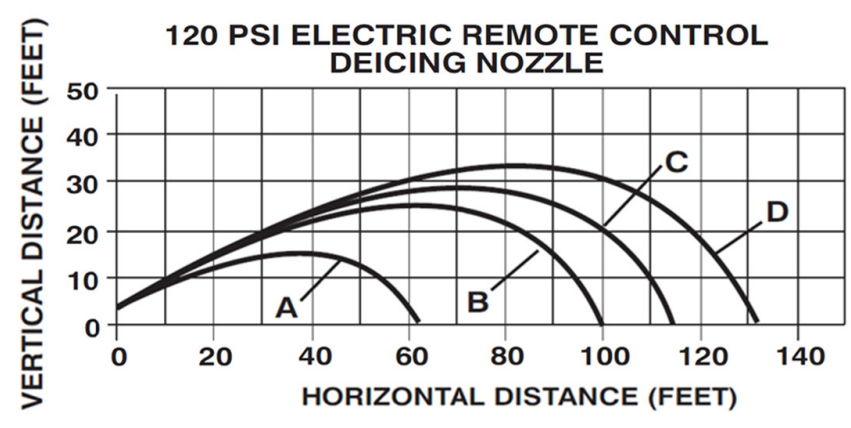

\begin{tabular}{|c|c|c|c|}
\hline CURVE & $\begin{array}{c}\text { GPM } \\
\text { FLOW }\end{array}$ & $\begin{array}{c}\text { PSI } \\
\text { INLET } \\
\text { PRESSURE }\end{array}$ & $\begin{array}{c}\text { LBS } \\
\text { REACTION }\end{array}$ \\
\hline A & 20 & 50 & 7 \\
\hline B & 40 & 93 & 19 \\
\hline C & 60 & 106 & 31 \\
\hline D & 80 & 120 & 44 \\
\hline
\end{tabular}

Fig. 7. Load imbalance moment arm for the GRIFF 135, $y$ and $z$ planes.

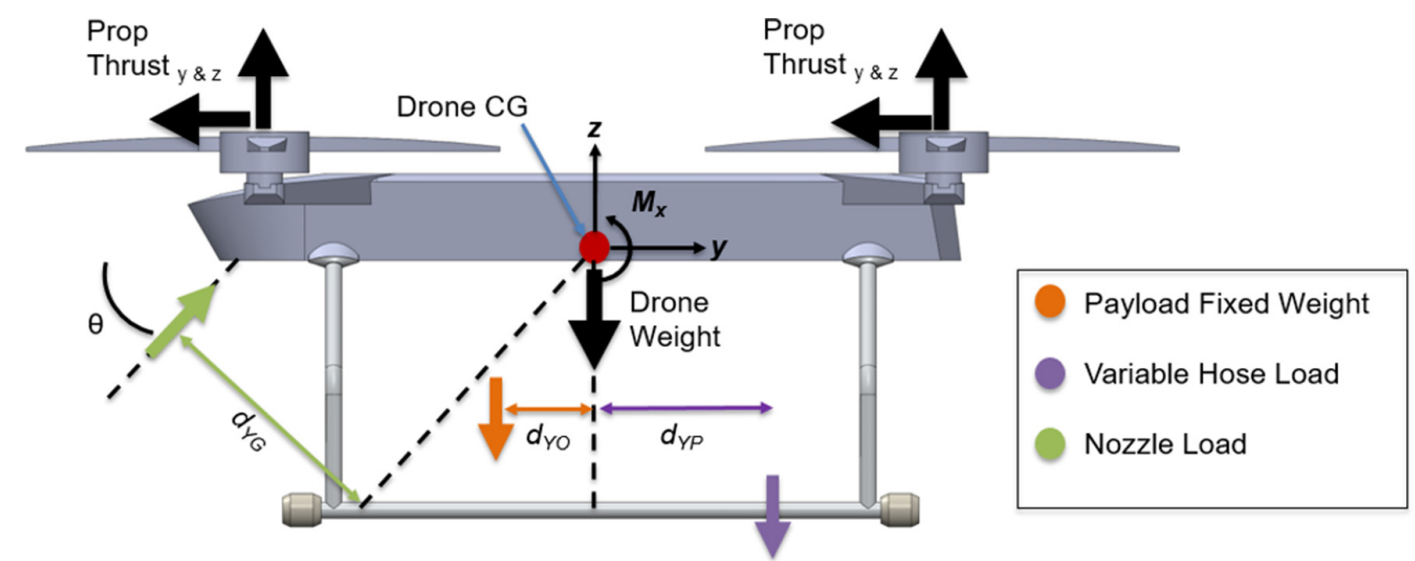

Fig. 8. Load imbalance moment arm for the GRIFF 135, $x$ and $z$ planes.

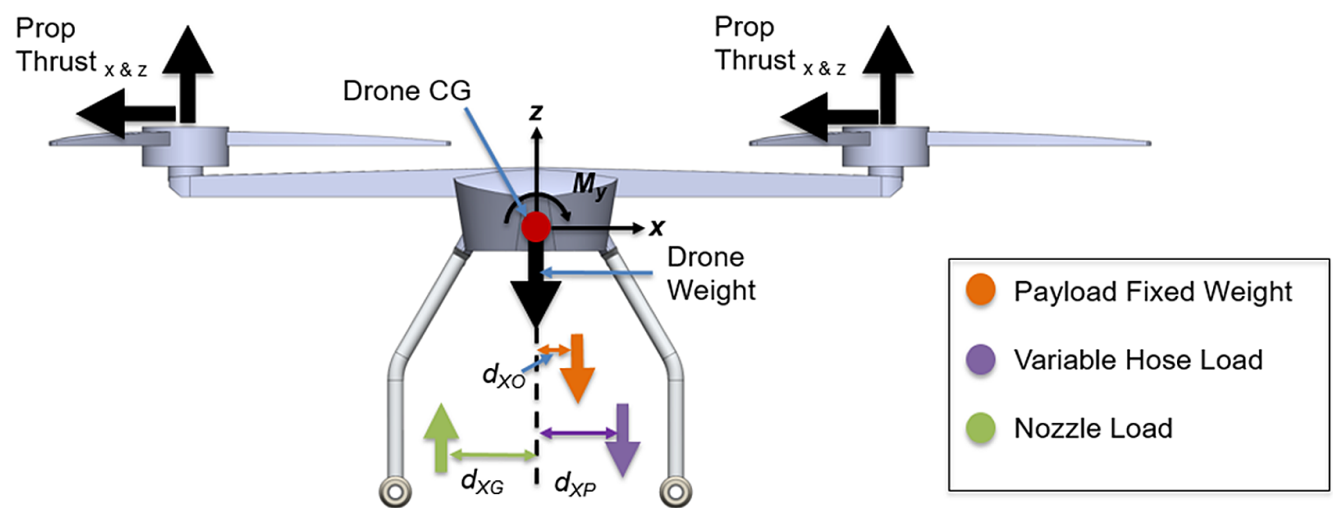


Fig. 9. Optimal load locations for the GRIFF 135, $y$ and $z$ planes.

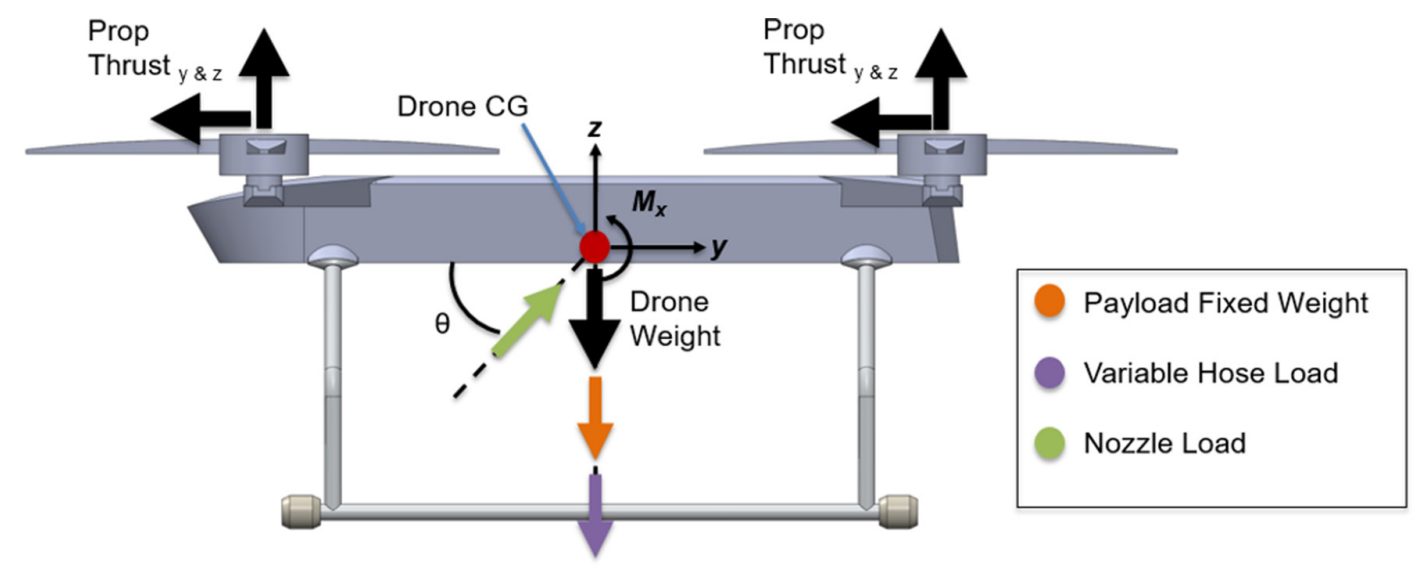

Fig. 10. Optimal load locations for the GRIFF 135, $x$ and $z$ planes.

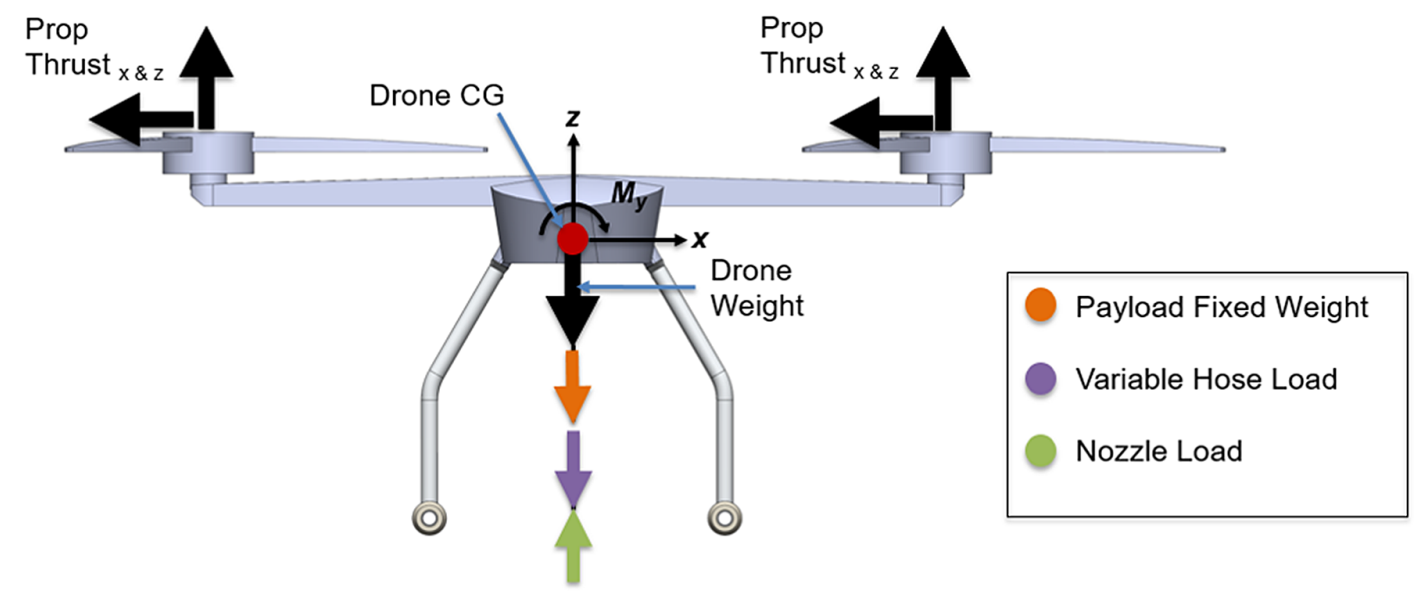

equal portion of the load, thus increasing flight stability and payload capacity. After careful consideration, it was decided to only test the payload in the minimal moment arm configuration for this reason. For this case, eqs. 7 and 9 apply along the length direction of the drone as well as the following equation (Fig. 9):

(12) $\Sigma \vec{M}_{x}=0$

while eqs. 7 and 11 apply along the width of the drone as well as the following equation (Fig. 10):

(13) $\Sigma \vec{M}_{y}=0$

The drone maximum takeoff weight is $135 \mathrm{~kg}$, and its weight is around $80 \mathrm{~kg}$ including the battery pack; thus, it can support an additional $55 \mathrm{~kg}$. The estimated payload fixed weight of the system integrated onto the drone for de-icing/anti-icing operations is $20.8 \mathrm{~kg}$ (Table 5) for a remaining lifting capacity of $34.2 \mathrm{~kg}$. With the linear variation of the hose 
and fluid load at altitude of approximately $1.316 \mathrm{~kg} / \mathrm{m}$, this results in a maximum flight

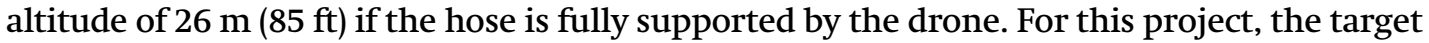

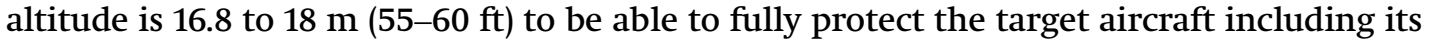
tail; therefore, the resulting design meets and exceeds this requirement. Additional capacity will be gained once the modular aspect of the designed setup is switched for a fixed permanent setup on the final prototype-through the removal of sliding bars and other components, since those are only installed in case something needs to be repositioned during or after the flight tests and will be removed once the design is final. Moreover, the battery pack accounts for around $40 \mathrm{~kg}$ of the $80 \mathrm{~kg}$ total weight of the drone. By tethering the drone, as discussed previously, the power supply to the drone could be provided directly from the ground, freeing additional weight if the tether is lighter than the battery pack, as is likely. Again, tethering the drone is a real possibility to increase the safety of operations at airports and to increase the flight duration of the drone with its power supplied from the ground as well as providing the additional power required to ensure its protection from different freezing and frozen precipitation. This significant extra payload capability will allow the drone to gain extra horizontal movement capacity relative to the tank. With the actual design, the tank might have to be moved around the aircraft during spraying, either by an airport worker or by having the tank on an electronic chariot (or something similar). However, the extra flexibility, both from the extended altitude calculated and the additional potential, should greatly reduce the required movement of the tank during the process or even completely remove the need to, especially if two drones can freely operate on each side of the aircraft each having only one side to protect.

\subsubsection{De-icing/anti-icing drone payload design and integration}

The drone payload has been designed to be modular so that the setup and design during experimentation could be quickly modified, if necessary. In addition, if a component or section of the payload is shown to be inadequate during testing, it can be easily modified or replaced without affecting the rest of the assembly. To minimize any side-to-side imbalance, the nozzle and hose attachment points have been positioned along the drone longitudinal center plane (YZ plane, see Fig. 11) on individual sleds. Both the nozzle sled and the hose sled are clamped to a rail system attached under the drone and can move independently from one another along the drone's longitudinal axis only for safety in case adjustments are required after flight tests. The rail system is attached to the drone anchor points using quick-release pucks provided by the drone's manufacturer. The rail system is constructed using simple $25.4 \mathrm{~mm}\left(1^{\prime \prime}\right)$ outside diameter aluminum pipes and can be cut to the required length. The hose sled and the nozzle sled are connected using standard commercially available aluminum National Pipe Tapered (NPT) fittings commonly used in plumbing applications (Fig. 12). Aluminum was selected over steel and stainless steel as the main material owing to its lightness and corrosion resistance. Plastics were rejected due to the high fluid temperatures (close to $100{ }^{\circ} \mathrm{C}$ ) and low ambient temperatures $\left(-40^{\circ} \mathrm{C}\right)$ under which the system must operate. The spacing between the hose sled and nozzle sled can be changed easily by undoing the center link and replacing the center pipe for one having a different length. The quick release is also shown in Fig. 11.

A reducing tee fitting along with a combination probe was plumbed inline between the hose sled and the nozzle sled to monitor both pressure and temperature directly at the nozzle during operation. The TFT combination nozzle is mounted in the nozzle sled using a swiveling $90^{\circ}$ elbow fitting, which allows it to tilt. With the help of the tilt bracket, the nozzle can be fixed at any $7.5^{\circ}$ increment from $0^{\circ}$ (horizontal) to $90^{\circ}$ (vertical), as shown in Fig. 13. The fan angle of the spray from the nozzle can also be adjusted. A small length of hose $(1.2 \mathrm{~m})$ is attached to the hose sled using an NPT tank bulkhead fitting. This small 
Fig. 11. Diagram showing the hose and nozzle being aligned with the drone's longitudinal center plane: $(a)$ bottom view and $(b)$ front view.

(a)

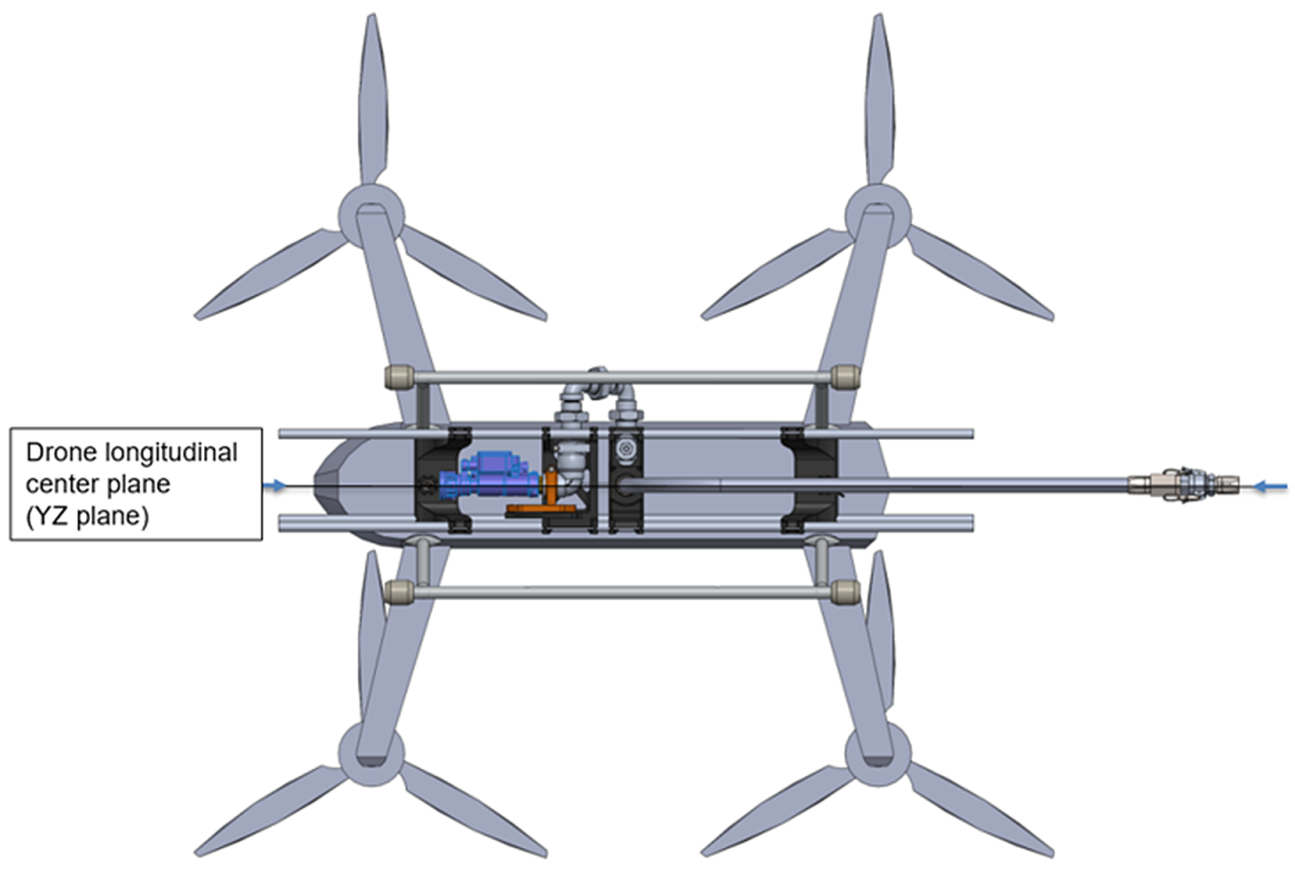

(b)

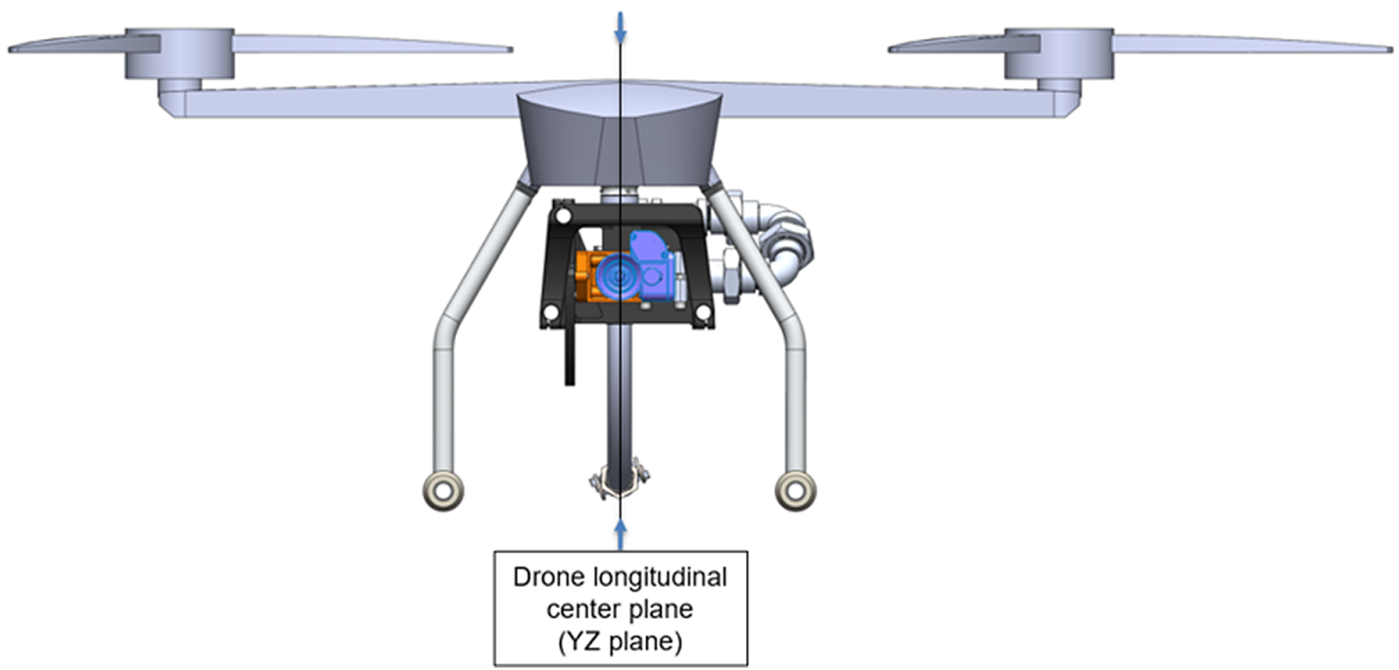

length of hose extends behind the drone and allows the drone operator to easily access and connect or disconnect the drone/payload assembly from the remaining $16.8 \mathrm{~m}$ or more of hose on a reel without having to reach awkwardly under the drone (Fig. 14). The hoses can be quickly connected or disconnected without any required tools by using the cam and groove fitting. A straight swiveling coupler fitting is also used between one of the hoses and the cam and groove connection to prevent the hose from twisting while in use.

- Published by Canadian Science Publishing 
Fig. 12. De-icing drone payload components: $(a)$ side view and $(b)$ isometric view.

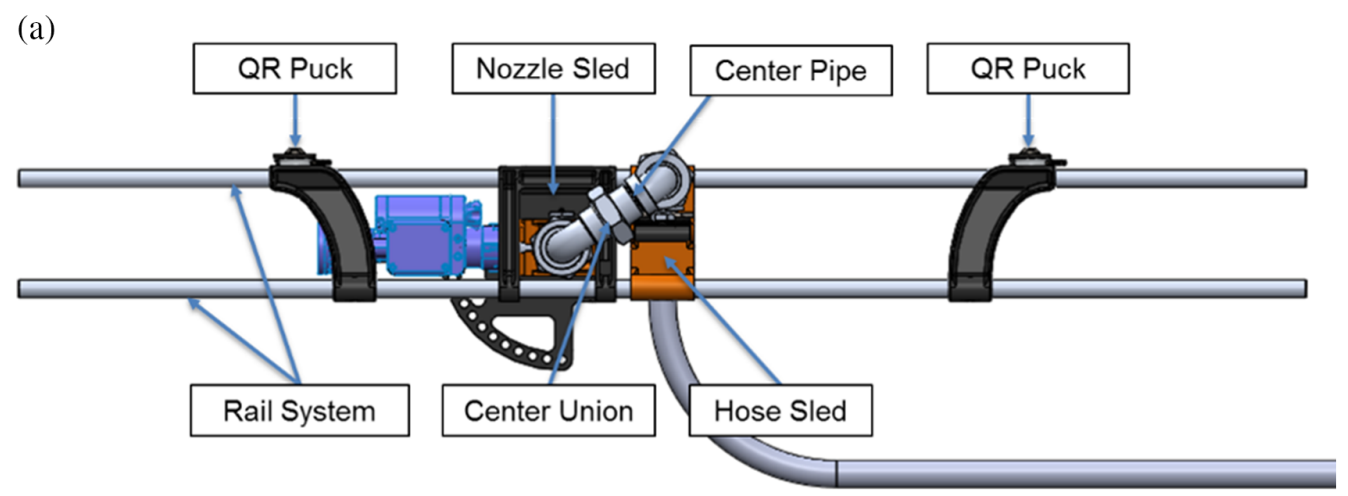

(b)

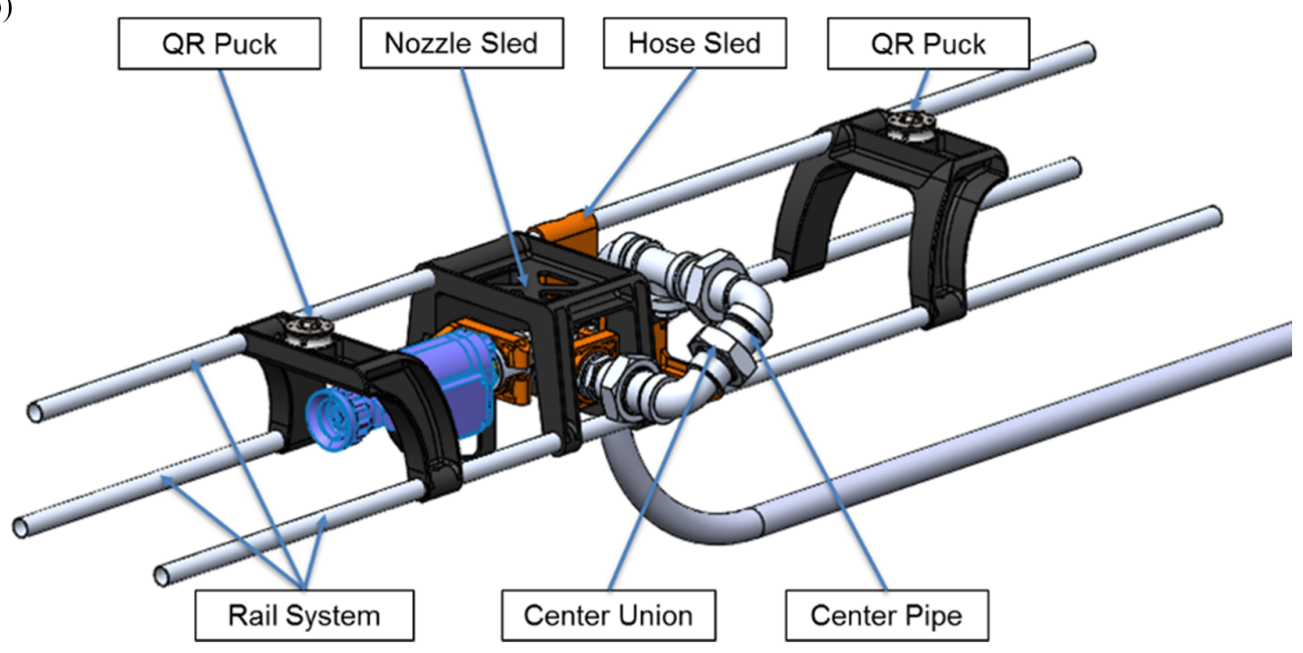

Finally, the drone also required modifications to ensure compatibility with the payload. Custom legs were provided by Griff to raise the drone by $190 \mathrm{~mm}$ to generate enough clearance underneath the drone to receive the selected hose minimum bend radius and nozzle length. This new landing gear, specifically designed for this project by the OEM drone manufacturer, has all the same features and benefits than the original one. The system integrated with the drone is presented in Fig. 15.

\section{Conclusion}

Ground de-icing/anti-icing operations at most northern remote locations and smaller airports is currently very difficult owing to the costly and extensive infrastructure required. The military and aviation industry require solutions to this problem. Canada's Department of National Defence has mandated and funded a three-month initial phase study through their Innovation for Defence Excellence and Security program to design a concept allowing aircraft de-icing/anti-icing operations at remote and northern sites. We designed a de-icing/anti-icing spraying system mounted on an unmanned aerial vehicle (drone) that can perform these required operations and be transported inside the aerial vehicles. This drone-based system respects the relevant industrial requirements and standards for ground de-icing/anti-icing operations. A drone suitable for de-icing/anti-icing tasks 
Fig. 13. Different tilt configurations of the nozzle: right side view.

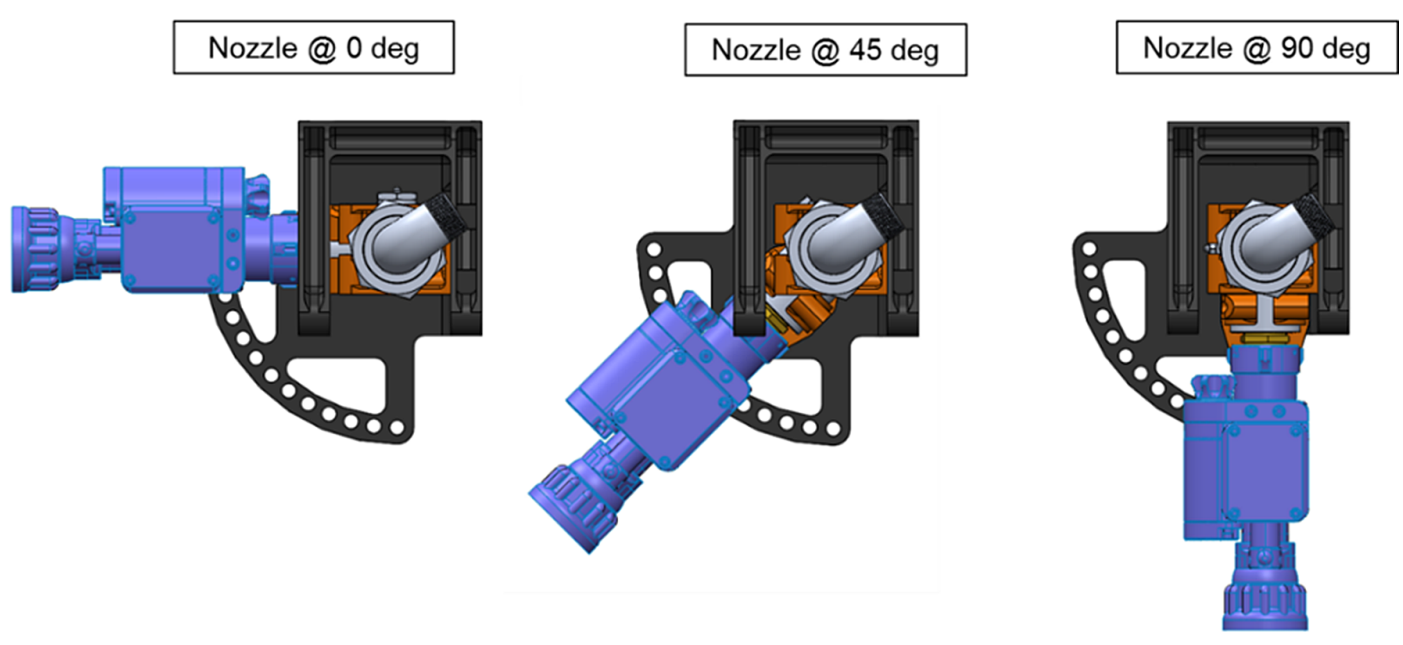

Fig. 14. Spraying system integrated with the drone with original landing gear.

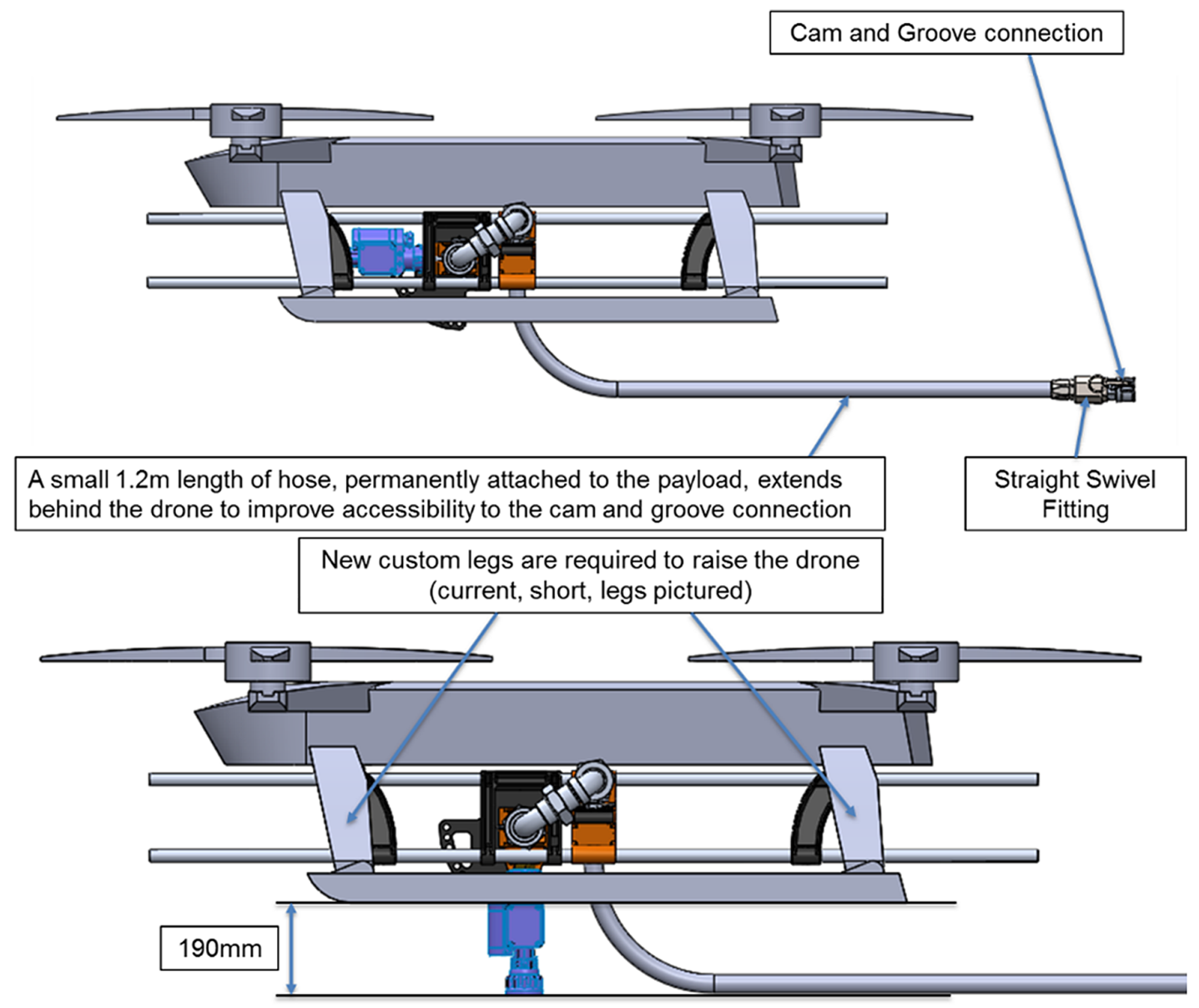

- Published by Canadian Science Publishing 
Fig. 15. Aircraft ground deicing/anti-icing system payload mounted on a drone.
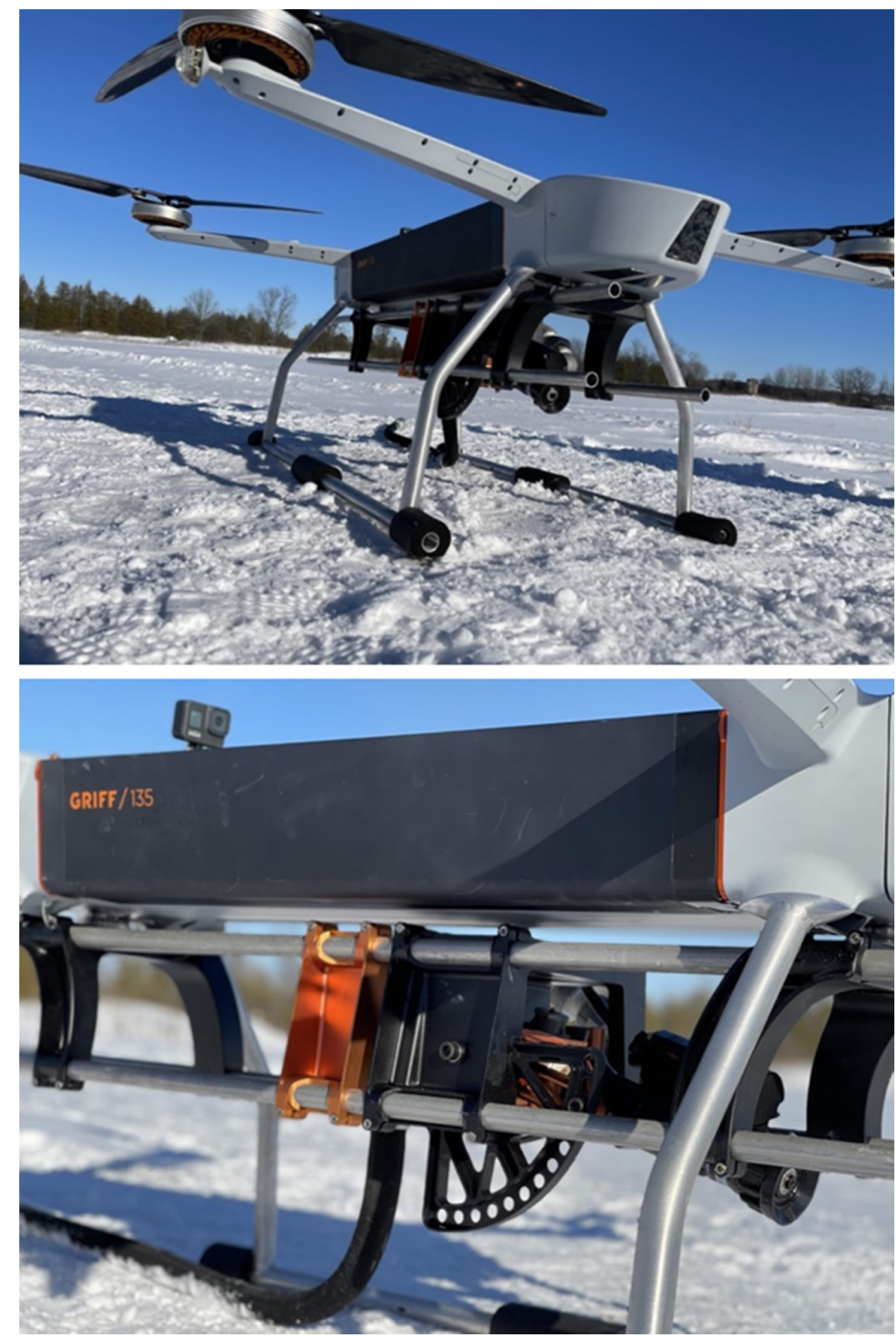

able to transport the required loads was selected. The components were mounted on the drone in a manner to minimize their effect on the drone's ability to fly and ensure an effective spraying process. The calculations demonstrated the ability of the drone to perform de-icing/anti-icing operations with the system as designed, principally by establishing that the performances of the spraying system meet the industry standards and by showing that the equivalent payload can be lifted by the drone. The final system design of a de-icing/ anti-icing system mounted on a drone theoretically satisfied the established characteristics 
for such a system and, with the fabrication of a test prototype, completed the initial three-month phase of this project.

For the second, and final, three-month phase of this project, the performance of the designed system will be evaluated under highly controlled laboratory conditions corresponding to the highest standards required by industry. The drone will then be submitted to flight tests for proof of concept with the full payload of the system. The drone will lift off and fly with the additional payload. The spraying system will then be applied to spray a target object. The results of these tests will be presented in another paper.

\section{Conflicts of interest}

The authors declare no conflict of interest.

\section{Funding}

This research was supported by the Department of National Defence, Innovation for Defence Excellence and Security (grant No. CH1-IDEaS-CFP3-1a CP-3215).

\section{References}

Aerones. 2018. “Aerones DRONE solutions.” Available from https://www.aerones.com/. Association of European Airlines. 1992. De-/anti-icing awareness. Association of European Airlines, France. Association of European Airlines. 2009. Recommendations for De-Icing/anti-Icing of Aircraft on the ground. Aviation, G. 2020. The Griff Fleet. Available from http://griffaviation.com/the-griff-fleet.

Cervantes, A., Garcìa, P., Herrera, C., Morales, E., Tarriba, F., Tena, E., and Ponce, H. 2018. A conceptual Desigh of a firefighter drone. 15th International Conference on Electrical Engineering, Computing Science and Automatic Control (CCE). Mexico City.

Custers, B. 2016. The future of Drone use: oppptunities and threats from ethical and legal perpectives. Springer, NY. Eaton. 2020. Aeroquip 1503-16. Available from http://www.eatonpowersource.com/products/filter/hydraulic-hose/ details/1503-16/.

Eaton. 2020. Aeroquip 1503-20. Available from https://www.eatonpowersource.com/products/filter/hydraulic-hose/ details/1503-20/.

Environment and Climate Change Canada. 2021. 1981-2010 climate normals \& averages. Available from https:// climate.weather.gc.ca/climate_normals/index_e.html.

Faiçal, B.S., Freitas, H., Gomes, P.H., Mano, L.Y., Pessin, G., de Carvalho, A.C.P.L.F., Krishnamachari, B., and Ueyama, J. 2017. An adaptive approach for UAV-based pesticide spraying in dynamic environments. Comput. Electron. Agric. 138: 210-223. doi:10.1016/j.compag.2017.04.011.

Gidinceanu, C.-P. 2019. De-icing and maintenance of wind turbines with drones.Aalborg University, Master.

Government of Canada, D. o. N. D. 2019. Breaking the ice - ground solutions for removing frozen contaminants from aircraft. Available from https://www.canada.ca/en/department-national-defence/programs/defence-ideas/ past-opportunities/ice-accumulation-on-aircraft.html.

Hayat, S., Tyanmaz, E., and Muzaffar, R. 2016. Survey on unmanned aerial vehicle network for civil applications: a communication viewpoint. IEE Commun. Surveys Tuts. 18: 2624. doi:10.1109/COMST.2016.2560343.

Jorge, H.G., de Santos, L.M.G., Álvarez, N.F., Martínez Sánchez, J., and Medina, F.N. 2021. Operational study of Drone spraying application for the disinfection of surfaces against the COVID-19 Pandemic. Drones, 5(1): 18.

Liu, Y., Li, L., Li, H., and Hu, H. 2018. An experimental study of surface wettability effect on dynamic ice accretion process over an UAS Propeller model. Aerosp. Sci. Technol. 73: 164-172. doi:10.1016/j.ast.2017.12.003.

Liu, Y., Li, L., Ning, Z., Tian, W., and Hu, H. 2017. An experimental study of the transient Ice acretion process over the Blade surface of a rotating UAS propeller. 55th AIAA Aerospace Science Meeting. Texas, USA. pp. 1-18.

Liu, Y., Li, L., Ning, Z., Tian, W., and Hu, H. 2018. Experimental investigation on the dynamic icing process over a rotating propeller model. J. Propuls. Power, 34(4): 933-946. doi:10.2514/1.B36748.

Meteoblue. 2021. Simulated historical climate \& weather data. Available from https://www.meteoblue.com/en/ weather/historyclimate/climatemodelled.

Restás, Á., Szalkai, I., and Óvári G. 2021. Drone application for spraying disinfection liquid fighting against Covid-19 pandemic - theoretic approach. doi:10.3390/drones5030058.

SAE International. 1986. (R) Aircraft deicing vehicle - self-propelled. p. 17. Avaialbe from SAE.ORG.

SAE International. 1992. Aircraft deicing/anti-icing methods with fluids, for large transport aircraft.Society of Automotive Engineers, Warrendale, PA. p. 19.

SAE International. 2008. Qualification process for SAE AMS1428 Type II, III and IV fluids.

SAE International. 2012. AMS 1424 deicing/anti-icing fluid, aircraft, SAE Type I, Society of Automotive Engineers.

SAE International. 2016. AMS 1428 fluid aircraft deicing/anti-Icing, non Newtonian (Pseudoplastic), SAE Types II,

Type III and Type IV.

SAE International. 2018. AS6285, aircraft ground deicing/anti-Icing processes. 42. 
SAE International. 2019. AS5901D water spray and high humidity endurance test methods for SAE AMS1424 and SAE AMS1428 Aircraft Deicing/Anti-icing Fluids. 13.

SAE International. 2020. SAE AMS 1424 Fluid, Aircraft Deicing/Anti-Icing, SAE Type I. REV. R. 16.

Tips, T.F. 2007. Manual: ice-control Nozzles. Available from https://legacy.tft.com/literature/library/files/LIB205_rev08.pdf.

Tips, T.F. 2020. Task force tips deicing. Available from http://deicing.tft.com.

Transport Canada. 2004. Aircraft critical surface contamination training for Aircrew and Groundcrew TP10643E. 138. Available from https://tc.canada.ca/en/aviation/publications/when-doubtsmall-large-aircraft-aircraft-criticalsurface-contamination-training-tp-10643/foreword.

Transport Canada. 2019. TP 14052E: guidelines for aircraft ground icing operations. Ottawa. 161 p. Available from https:/tc.canada.ca/sites/default/files/2021-09/TP-14052E-6TH_EDITION.pdf. 